\title{
Pd Model Catalysts: Effect of Aging Duration on Lean Redispersion
}

\author{
Jason A. Lupescu ${ }^{1,2,}$, , Johannes W. Schwank ${ }^{1}$, Galen B. Fisher ${ }^{1}$, Xiaoyin Chen ${ }^{1}$, \\ Sabrina L. Peczonczyk ${ }^{2}$ and Andy R. Drews ${ }^{2}$ \\ ${ }^{1}$ University of Michigan, Ann Arbor, MI 48109 USA \\ ${ }^{2}$ Ford Motor Company, Dearborn, MI 48124 USA
}

${ }^{*}$ Corresponding author:

Jason Lupescu

Ford Motor Company, RIC Bldg., MD3179, P.O. Box 2053, Dearborn, MI 48121

E-mail: jlupescu@ford.com; Tel: +1-313-323-1503 


\begin{abstract}
An automotive three-way catalyst (TWC) deteriorates as a function of temperature, time and aging environment. While much effort has gone into formulating durable exhaust catalysts, relatively little attention has been paid to controlling the aging environment on the vehicle with techniques currently in use to protect the catalyst and counteract the increasing demands for higher fuel economy (e.g., overfueling to reduce exhaust temperatures). New engine control methods that are designed to minimize aging may be possible that can reduce the extent of catalyst deactivation and provide a lean environment capable of redispersing many of the precious metal particles. To develop improved engine control methods, detailed experimental information is needed to map the response of the catalyst to different aging conditions. In this report, we examine palladium-based model powder catalysts on ceria-zirconia, which were exposed to three different exhaust compositions, lean-only, rich-only and redox, each at $700^{\circ} \mathrm{C}$ for three different durations, 20 minutes, 2 hours and 16 hours. Residual catalyst activity and metal-support interaction were probed with Water Gas Shift (WGS) reaction and Oxygen Storage Capacity (OSC) measurements. The Pd metal particle size and dispersion were estimated by $\mathrm{H}_{2}$ chemisorption and XRD line broadening. Lean catalyst treatments at $550^{\circ} \mathrm{C}$ and $700^{\circ} \mathrm{C}$ were applied to determine the effect on $\mathrm{Pd}$ size and catalyst activity. An infrared study of $\mathrm{CO}$ adsorption onto the catalysts was used to identify whether Pd crystallite facets were covered by the support after exposure to the redox aging environment then again after the lean treatments were applied. The aging temperature and reducing gas environment significantly deteriorated catalytic activity through a combination of metal oxidation state effects and support interactions, while the aging duration was linked to the extent of $\mathrm{Pd}$ sintering reversibility through lean treatments. These insights provide a basis to develop engine control and aftertreatment design strategies to avoid severe aging modes and determine how often to actively intervene to regenerate the catalyst.
\end{abstract}

Keywords: Palladium, ceria-zirconia, redispersion, TWC, aging 


\section{Introduction}

The automotive catalytic converter, or Three-Way Catalyst (TWC), works in unison with engine controls that manage exhaust gas oxygen $\left(\mathrm{O}_{2}\right)$ concentration to abate regulated fuel combustion products like carbon monoxide (CO). The TWC washcoat contains a noble metal catalyst (i.e., Pd) impregnated onto a high surface area support material composed of alumina $\left(\mathrm{Al}_{2} \mathrm{O}_{3}\right)$, oxygen storage capacity (OSC) promoters including mixtures of ceria and zirconia (CZO), and durability stabilizers such as rare earth oxides lanthana $\left(\mathrm{La}_{2} \mathrm{O}_{3}\right)$ and yttria $\left(\mathrm{Y}_{2} \mathrm{O}_{3}\right)$ [1]. The on-board engine control computer is essential to enable brief, controlled cycling of fuel-rich (oxygen deficient) and fuel-lean (excess oxygen) combustion exhaust to perform simultaneous oxidation and reduction reactions [1,2]. Over time, the TWC typically shows decreased efficiency of these reactions under the same exhaust environment, which is linked to deactivation. TWC deactivation modes include noble metal sintering $[3,4]$, poisoning by fuel and oil additives [ 5], loss of surface area and OSC component sintering [1, 2, 6 ]. Characterization studies of full useful-life aged automotive TWCs revealed that the dispersion of noble metals had fallen to only about $1-5 \%[7,8]$, revealing that the vast initial amount of metal was buried inside large metal agglomerates and lost to involvement in gas-phase reactions. While in similar studies, OSC component sintering was explained by loss of contact between the noble metal and the OSC component $[9,10,11,12,13,14]$, and by partial migration of OSC component materials, covering the noble metal $[15,16,17]$.

Although TWC deactivation is largely irreversible, prolonged exposure to an oxidative gas environment can cause changes to the metal that result in partial reactivation. An increase in the Pd metal dispersion was observed following dry oxygen treatment that resulted in a lower temperature required for $50 \%$ conversion of combustion pollutants [18, 19]. In another study, $\mathrm{Pd}$ particles on an $\mathrm{Al}_{2} \mathrm{O}_{3}$ support heated in a feed containing oxygen were observed to transform into $\mathrm{PdO}$ above $325^{\circ} \mathrm{C}$, and upon further heating from $350^{\circ} \mathrm{C}$ to $800^{\circ} \mathrm{C}$ the particles wet and spread over the support $[20,21]$, ultimately shrinking to a size below the detection limit of the electron microscope used [22]. $\mathrm{Pd}$ redispersion is generally believed to begin at the temperature when $\mathrm{Pd}$ particles oxidize to $\mathrm{PdO}$, and this temperature depends upon the $\mathrm{Pd}$ particle size [20, 23]. $\mathrm{PdO}$ is stable up to $800^{\circ} \mathrm{C}$ in air and does not sinter or emit adatoms [24]. This enables $\mathrm{PdO}$ to wet and spread over the support. The onset temperature of redispersion was found to decrease with increasing Pd metal dispersion (decreasing Pd crystal size) [20, 23]. $\mathrm{Pd}$ redispersion is therefore thought to occur through the oxide form as it does not occur above the temperature of $\mathrm{PdO}$ decomposition $[20,21]$, which is both a function of the support material and gas phase oxygen concentration $[21,25,26]$. To be of automotive relevance, intentional $\mathrm{Pd}$ redispersion would ideally be performed within the time scale of an engine deceleration fuel cut, which was shown to expose the catalyst to air for about 2-10 seconds on the FTP-75 (federal drive cycle) [27]. Newton et al. performed redox cycling at $400^{\circ} \mathrm{C}$ with $2 \mathrm{wt} \% \mathrm{Pd} / \mathrm{Al}_{2} \mathrm{O}_{3}$ and observed that the Pd particle size immediately dropped from an average of 600 atoms per particle to about 20 atoms per particle within 2 seconds of the lean cycle onset, coinciding with the $\mathrm{Pd}$ to $\mathrm{PdO}$ transition [28]. If the $\mathrm{Pd}$ oxidation rate can be measured, then the $\mathrm{Pd}$ redispersion rate can be estimated and used as part of an engine control strategy to optimize the redispersion process.

The goal of this investigation was to determine how characteristics of deactivated model Pd catalysts aged for different durations were affected by exposure to post-aging oxidizing gas environments. Active intervention into the TWC aging process using periodic oxidative engine exhaust events may be useful to restore the catalyst conversion efficiency. However, the limits to the effectiveness of this regeneration method are unknown. To be fully effective, a detailed understanding of the Pd particle size response is needed. There is no one technique that can 
derive the true Pd size on CZO supports, so a synthesis of multiple, yet limited techniques, were used so that a consistent interpretation could be made. This requires evaluation of a TWC to characterize the Pd particle size in concert with probe reactions to assess the metal-support interface and measure residual catalyst activity, support surface area changes and $\mathrm{PdO}$ formation rate. While these evaluations may suggest a strong metal support interaction (SMSI) with Ce migrating and decorating the Pd surface during reducing conditions [15, 29, 30, 31, 32], obtaining direct evidence with high resolution electron microscopy is extremely difficult due to poor contrast between $\mathrm{Pd}, \mathrm{Zr}$ and $\mathrm{Ce}$. However, $\mathrm{CO}$ adsorption onto the surface of supported $\mathrm{Pd}$ catalysts during acquisition of infrared spectra has shown capability to identify the accessible $\mathrm{Pd}$ facets [33, 34] and provide evidence of coverage via SMSI [30]. Here, we characterize these changes and identify the most severe deactivation modes so that they can be avoided through engine control methods.

\section{Experimental}

\subsection{Preparation of Model TWC Samples}

A model powder catalyst of $1.5 \mathrm{wt} \% \mathrm{Pd}$ on ceria-zirconia $(\mathrm{Pd} / \mathrm{CZO})$ was prepared at a Ford OEM supplier laboratory by incipient-wetness impregnation of the ceria-zirconia $\left(\mathrm{Ce}_{0.5} \mathrm{Zr}_{0.5} \mathrm{O}_{2}\right)$ support with a palladium solution free from chlorides. After drying, this catalyst was calcined at $500^{\circ} \mathrm{C}$ for 4 hours in air to fix the $\mathrm{Pd}$ on the $\mathrm{CZO}$ material. Uncatalyzed ceriazirconia $\left(\mathrm{Ce}_{0.5} \mathrm{Zr}_{0.5} \mathrm{O}_{2}\right)$ powder was also used as a standard to acquire baseline characterization data. The powders were then sieved to obtain particles between 40-60 mesh (250-420 microns).

\subsection{TWC Aging Procedures}

Catalyst aging environments were established in a continuous flow reactor at $700^{\circ} \mathrm{C}$ with a tight air-fuel modulation to represent operating conditions of an automotive close-coupled catalytic converter. Three aging gas compositions were used: lean-only $\left(0.1 \% \mathrm{O}_{2}, 10 \% \mathrm{H}_{2} \mathrm{O}\right.$ and $\left.\mathrm{N}_{2}\right)$, rich-only $\left(0.15 \% \mathrm{CO}, 0.05 \% \mathrm{H}_{2}, 10 \% \mathrm{H}_{2} \mathrm{O}\right.$ and $\left.\mathrm{N}_{2}\right)$ and redox conditions where the lean and rich feeds were alternated in 10 minute step pulses. The $\mathrm{CO}$ gas stream was scrubbed of iron carbonyls. A round bottomed quartz boat measured $100 \mathrm{~mm}$ long, $17 \mathrm{~mm}$ wide and $5 \mathrm{~mm}$ tall was loaded with $1.50 \mathrm{~g}$ of catalyst powder and placed inside a $19 \mathrm{~mm}$ ID quartz reaction tube in the heating zone of the surrounding oven with a 1/16 inch diameter thermocouple placed over the boat in the aging gas stream and a 1/32 inch diameter thermocouple bent into the boat with the tip buried in the powder. Sample sets were aged for 20 minutes, 2 hours and 16 hours, respectively.

\subsection{TWC Preconditioning}

Since gasoline engines operate close to stoichiometry, the catalyst OSC state is generally partly depleted. Therefore at the beginning of all characterization and activity measurements for this study, all samples were initially in a reduced state produced by exposure to $9 \% \mathrm{H}_{2}$ in argon at $300^{\circ} \mathrm{C}$ for 30 minutes flowing at $0.22 \mathrm{~L} / \mathrm{min}$ to remove all surface oxygen. The samples were then cooled in argon to room temperature.

\subsection{TWC Characterization Techniques}


The phase identification of the $\mathrm{Pd} / \mathrm{CZO}$ catalysts was confirmed by X-ray diffraction (XRD) pattern analysis. A Rigaku Miniflex II diffractometer was used with a Cu Ka X-Ray $(\lambda=$ $1.5406 \AA$ ) radiation source set at $30 \mathrm{kV}$ and $15 \mathrm{~mA}$. A catalyst sample mass of $0.1 \mathrm{~g}$ was wetmilled with a mortar and pestle in ethanol then dripped onto an off-axis cut silicon crystal sample substrate and dried. Scans were performed with a step size of $0.005^{\circ} 2 \theta$ at a scan speed of $1^{\circ} 2 \theta /$ min from $5^{\circ} 2 \theta$ to $90^{\circ} 2 \theta$.

The surface characteristics of the catalysts were determined by $\mathrm{N}_{2}$ physisorption, $\mathrm{X}$-ray photoelectron spectroscopy (XPS) and Diffuse Reflectance Infrared Fourier Transform Spectroscopy (DRIFTS). The BET specific surface area and BJH pore volume (for pores between 17-300A) were determined with a Micromeritics ASAP2420 instrument using $\mathrm{N}_{2}$ adsorption at 77K. A 48-point adsorption and 33-point desorption isotherm plot was generated across a range of 0.1-0.9 $\mathrm{P} / \mathrm{P}_{0}$. Elemental composition and chemical state information were determined with a Kratos AXIS 165 Electron Spectrometer using a monochromatic Al Ka $(1486.6 \mathrm{eV})$ X-ray excitation source operated at $12 \mathrm{kV}, 20 \mathrm{~mA}(240 \mathrm{~W})$. Each sample was pressed into a pellet and then mounted onto sticky double sided pressure sensitive adhesive tape. Data were collected using pass energies of $80 \mathrm{eV}$ or $20 \mathrm{eV}$ to obtain survey or high resolution spectra, respectively. All spectra were acquired using charge neutralization with an electron flood source. Elemental quantification of the high resolution spectra was accomplished using CASAXPS software Version 2.3.16, using routines based on Scofield photoionization cross-section values. A Shirley type background was used to fit all high resolution spectra. The $\mathrm{Zr} 3 p$ fit was first determined from a CZO standard using 60\% Gaussian and $40 \%$ Lorentzian line shapes with an area ratio of 0.5 , a full width at half maximum (FWHM) constrained between $0.6-2.8$, and a peak separation of $13.4 \mathrm{eV}$. The remaining area under the envelope was then fit by adding $\mathrm{Pd} 3 \mathrm{~d}$ peaks. The Pd $3 d$ species was fit with a doublet using $60 \%$ Gaussian and $40 \%$ Lorentzian line shapes with an area ratio of 0.667 , a FWHM constrained within 0.6-2.8, and a peak separation of $5.2 \mathrm{eV}$. Binding energies were referenced to the aliphatic $\mathrm{C} 1 \mathrm{~s}$ peak at $284.6 \mathrm{eV}$ [35]. Infrared spectra were collected with a Nicolet 6700 FTIR spectrometer with Auxiliary Experiment Module including a praying mantis cell to facilitate gas exchange to and heating of the sample. Fine powder catalyst samples recovered from the XRD analysis were poured into the praying mantis sample cup onto a supporting screen. Clean samples were prepared as follows: 1) $25 \% \mathrm{H}_{2}$ in nitrogen fed to the sample for 16 hours at $400^{\circ} \mathrm{C}, 2$ ) switched to $1 \% \mathrm{O}_{2}$ in nitrogen carrier gas to burn off saturated carbonate and formate surface species for an hour, 3) switched off $\mathrm{O}_{2}$ and heated the sample cell to $600^{\circ} \mathrm{C}$ for one hour in nitrogen-only to decompose surface $\mathrm{PdO}$, 4) sample was cooled to $22^{\circ} \mathrm{C}$ and stabilized over one hour. The IR spectra were collected with 64 scans at a resolution of $2 \mathrm{~cm}^{-1}$ in repeating loops every two minutes. A clean sample background was acquired first under flowing nitrogen then $1 \% \mathrm{CO}$ was added to saturate the surface through two hours.

The mean $\mathrm{Pd}$ dispersion and particle size was determined with two methods. $\mathrm{H}_{2}$ chemisorption was performed using a Micromeritics ASAP2020 instrument with a static volumetric adsorption/out-gas/re-adsorption method described by Chen et al. [19]. Prior to analysis, each sample was first degassed in $\mathrm{N}_{2}$ at $500^{\circ} \mathrm{C}$, then cooled under vacuum to 1 microtorr prior to evaluation. Each sample was then reduced at $350^{\circ} \mathrm{C}$ in pure $\mathrm{H}_{2}$, (assumed to not sinter the Pd particles) then exposed to vacuum at 1 microtorr to remove Pd hydride prior to $\mathrm{H}_{2}$ chemisorption measurements at $35^{\circ} \mathrm{C}$. A hydrogen adsorption stoichiometry value of 1 was assumed, for one adsorbed $\mathrm{H}$ atom per every one surface $\mathrm{Pd}$ atom. This technique is an improvement upon the classic $\mathrm{H}_{2}-\mathrm{O}_{2}$ titration method and avoids problems of $\mathrm{H}_{2}$ spill-over and $\mathrm{Pd}$ hydride formation from interfering with the irreversible adsorbed $\mathrm{H}_{2}$ calculation [36, 37]. The differential results were used to report $\mathrm{Pd}$ dispersion and size to exclude physisorbed $\mathrm{H}_{2}$ on the support. $\mathrm{H}_{2}$ chemisorption was used for all samples since we found that $\mathrm{CO}$ chemisorption 
significantly overestimated the Pd dispersion on the CZO supports, probably due in part to $\mathrm{CO}$ adsorption on CZO forming stable carbonate species [38]. Post-process curve fitting of the XRD pattern Pd [111] peak was performed with the Rigaku PDXL software program. The software calculations used for estimating mean $\mathrm{Pd}$ crystalline length from XRD pattern line broadening was based on the Scherrer equation [39]. The shape factor used was 0.89 for spherical crystallites and the peak integral method was used to determine peak breadth. The instrument broadening was corrected with a $\mathrm{LaB}_{6}$ calibration standard.

\subsection{High Temperature X-Ray Diffraction (HTXRD)}

HTXRD was measured using a Bueler HDK furnace attachment mounted to a Scintag $\mathrm{X} 1$ diffractometer equipped with a low divergence $\left(0.03^{\circ}\right)$ beam of $\mathrm{Cu}$-Ka radiation produced using an Osmic collimating optic. Data were collected using an Inel $120^{\circ}$ position sensitive detector with a $250 \mathrm{~mm}$ radius. X-Ray source settings were $45 \mathrm{kV}$ and $40 \mathrm{~mA}$. Scans were performed with an interval of $0.015^{\circ} 2 \theta$. Samples were prepared by wet-milling $20 \mathrm{mg}$ of powder in ethanol and pipetting it onto a $1 \mathrm{~mm}$ thick, $10 \mathrm{~mm}$ square silicon carbide single crystal slide and allowing to dry. The slide was then placed onto the primary heating strip that includes a Pt thermocouple welded to its underside for feedback temperature control. Calibration of the sample temperature was verified to be within $+/-5^{\circ} \mathrm{C}$ by comparing the observed melting transition in its HTXRD pattern to the known melting point of high purity aluminum. Gas flow into the furnace chamber was controlled with MKS mass-flow controllers at a total flow rate of 1 $\mathrm{L} / \mathrm{min}$. The internal volume of the furnace chamber was about $1.5 \mathrm{~L}$. Oxidation experiments were conducted after an initial in-situ 1 hour reduction in $250 \mathrm{sccm}$ of $5 \% \mathrm{H}_{2}$ in balance $\mathrm{N}_{2}$ at $300^{\circ} \mathrm{C}$. Prior to each experiment, the chamber was purged with pure $\mathrm{N}_{2}$ for 5 minutes and the heating strip temperature was adjusted to the temperature of interest. HTXRD data were recorded with one scan during the purge to obtain the initial $\mathrm{Pd}$ [111] peak size and the feed gas was switched to dry air simultaneously with the beginning of an acquisition of repeated scans. The PdO phase fraction was calculated as one minus the quotient of the current integrated Pd peak area at time $t$ divided by the initial Pd peak area at time zero. Temperatures used to collect $\mathrm{HTXRD}$ data were in the range of $200^{\circ} \mathrm{C}$ to $350^{\circ} \mathrm{C}$.

\subsection{Thermogravimetric Analysis (TGA)}

Thermogravimetric analysis (TGA) of $\mathrm{PdO}$ decomposition and $\mathrm{Pd}$ reoxidation was carried out in a TA Q500 instrument. About $77 \mathrm{mg}$ of $\mathrm{Pd} / \mathrm{CZO}$ sample was placed on the sample pan. The sample was preconditioned by holding at $400^{\circ} \mathrm{C}$ in $10 \% \mathrm{O}_{2}$ environment and balance $\mathrm{N}_{2}$ at $100 \mathrm{~mL} / \mathrm{min}$ for 180-240 minutes for complete oxidation, then switching off $\mathrm{O}_{2}$ and holding in $\mathrm{N}_{2}$ for $60-120$ minutes at $50 \mathrm{~mL} / \mathrm{min}$ and heating to $700^{\circ} \mathrm{C}$ at a $5^{\circ} \mathrm{C} / \mathrm{min}$ ramp rate to decompose $\mathrm{PdO}$. The oven temperature was then adjusted to one of two desired measurement temperatures, $350^{\circ} \mathrm{C}$ or $700^{\circ} \mathrm{C}$, and held for 30 minutes before switching on the $10 \% \mathrm{O}_{2}$ to begin $\mathrm{Pd}$ oxidation. A Curie point temperature calibration using nickel (placed in the sample pan) confirmed the actual oven temperature is within $+/-2^{\circ} \mathrm{C}$ of the set value.

\subsection{TWC Activity Measurements}

The ASAP2020 quartz j-tube that was fit onto a flow reactor measured $10.5 \mathrm{~mm}$ ID and was loaded with a catalyst sample mass of $0.30 \mathrm{~g}$ between $6 \mathrm{~mm}$ redistributing layers of quartz wool. The bed height for each Pd/CZO sample was $4 \mathrm{~mm}$. Matheson dynablenders and flow controllers managed the gas flow through the system. A pyrex glass water bubbler was used to supply a stable stream of water vapor by saturation of the room temperature bulk gas stream. A solenoid set could be triggered to bypass the bulk gas around the water bubbler. The parts 
downstream of the water bubbler were stainless steel and wrapped in heat tape maintained at $150^{\circ} \mathrm{C}$ to prevent condensation. The $\mathrm{CO}$ gas stream was scrubbed of iron carbonyls. Two Ktype 1/32-inch diameter thermocouples were placed $16 \mathrm{~mm}$ before and $13 \mathrm{~mm}$ after the sample bed. A Hiden HPR20 quadrupole electron ionization mass spectrometer, pressure sensor and Horiba lambda sensor were used to sample the gas downstream of the j-tube. The HPR20 SEM detector measured five mass values in torr with a $2 \mathrm{~Hz}$ sampling rate at an inlet sampling pressure of 1E-5 torr. Two corrections were required to normalize the signals from other species into individual concentrations. First, the double excitation argon mass 20 value was scanned, which is $11 \%$ of the total argon level, rather than the typical mass 40 to get the measured argon value below the SEM detector limit of 1E-6 torr. Second, there was a CO and $\mathrm{CO}_{2}$ mass overlap of $11.4 \%$, so that amount of the $\mathrm{CO}_{2}$ value was subtracted from the $\mathrm{CO}$ value during data processing.

Oxygen storage capacity (OSC) measurements were carried out by alternating one minute lean or rich exposures, each separated by a one minute purge. The purge pulse was just the constant bulk carrier gas of $\mathrm{CO}_{2}$ and argon at $975 \mathrm{~mL} / \mathrm{min}$ while microvalves added a square step pulse of $\mathrm{CO}$ or $\mathrm{O}_{2}$ into the carrier gas at $25 \mathrm{~mL} / \mathrm{min}$. The bulk flow with lean pulse was $1 \% \mathrm{O}_{2}, 2 \% \mathrm{CO}_{2}$ and balance Ar. The bulk flow with rich pulse was $2 \% \mathrm{CO}, 2 \% \mathrm{CO}_{2}$ and balance Ar. The gas mixture was initially established at equilibrium over the catalyst sample at $50^{\circ} \mathrm{C}$. At least five $\mathrm{CO}$ pulses were measured at a fixed oven temperature before increasing the heating set point to the next $50^{\circ} \mathrm{C}$ increment, to a maximum set point of $400^{\circ} \mathrm{C}$.

Water gas shift (WGS) measurements were carried out with a constant feed of bulk carrier gas made up of $2 \% \mathrm{CO}, 2 \% \mathrm{CO}_{2}, 2.5 \% \mathrm{H}_{2} \mathrm{O}$ and argon at a total flow of $1 \mathrm{~L} / \mathrm{min}$. The bulk stream of argon and $\mathrm{CO}_{2}$ were fed through the water bubbler at $22^{\circ} \mathrm{C}$ to saturate the bulk gas and later downstream the $\mathrm{CO}$ was injected at the microvalve. The gas mixture was initially established at equilibrium over the catalyst sample at room temperature before triggering the start of the heating ramp at $10^{\circ} \mathrm{C} / \mathrm{min}$ to $400^{\circ} \mathrm{C}$.

Multiple OSC and WGS tests were run to determine whether the results drifted with changes to the sample caused by exposure to the gas stream at $400^{\circ} \mathrm{C}$. At least three $\mathrm{OSC}$ and WGS measurements were run on all samples. The last run was usually selected for comparison to the other sample aging conditions.

\section{Results}

\subsection{Catalyst Aging and Pd Redispersion Zone}

The catalyst aging and $\mathrm{Pd}$ redispersion conditions were compared to the results from Peuckert, which were used to develop an equation that predicts the bulk PdO decomposition temperature as a function of $\mathrm{O}_{2}$ concentration [26]. The results from this equation are plotted in Figure 1 for 1 atm total pressure. With just $0.1 \% \mathrm{O}_{2}$ in the lean-only and lean redox aging environments at $700^{\circ} \mathrm{C}$, the catalyst was above the bulk $\mathrm{PdO}$ decomposition temperature of about $620^{\circ} \mathrm{C}$. Lieske and Völter observed that Pd needed to be oxidized before redispersion would occur [23]. Incorporating the observations of Liekse and Völter, the area below the PdO decomposition line is shaded on Figure 1 and labeled as the "Pd Redispersion Zone". Entry into the lower Pd redispersion zone was tested with lean treatments at $550^{\circ} \mathrm{C}$ or $700^{\circ} \mathrm{C}$ with dry gas containing $21 \% \mathrm{O}_{2} / \mathrm{He}$ or zero air, an environment where the supported catalyst was well below the bulk $\mathrm{PdO}$ decomposition temperature of about $800^{\circ} \mathrm{C}$. Farrauto et al. demonstrated that 
there was a hysteresis between the $\mathrm{PdO}$ formation and decomposition temperature in air that varied with support. For example, PdO on ceria decomposed during heating at $775^{\circ} \mathrm{C}$ and $\mathrm{Pd}$ reoxidized during cooling at $730^{\circ} \mathrm{C}$ [25]. At lower oxygen concentrations near $0.5 \% \mathrm{O}_{2}$, the support effects diminish and a supported $\mathrm{PdO}$ decomposition temperature is closer to the bulk $\mathrm{PdO}$ value in Figure 1 as demonstrated by Colussi et al. on both $\mathrm{Pd} / \mathrm{Al}_{2} \mathrm{O}_{3}$ and $\mathrm{Pd} / \mathrm{CeO}_{2} / \mathrm{Al}_{2} \mathrm{O}_{3}$ catalysts [40]. Therefore, once the $\mathrm{PdO}$ had decomposed into metallic $\mathrm{Pd}$ around $620^{\circ} \mathrm{C}$ during heating under the redox or lean aging conditions at $700^{\circ} \mathrm{C}$, reoxidation of $\mathrm{Pd}$ would not occur until the temperature had dropped below the hysteresis temperature. Consequently, the supported Pd would likely be in the metallic state for all three aging environments.

\subsection{Surface Area and Pore Volume Characterization}

The BET surface area and BJH adsorption pore volume for each sample are listed in Table 1 below, both fresh and after exposure to various aging environments. The fresh Pd/CZO sample had a surface area of $91 \mathrm{~m}^{2} / \mathrm{g}$ and a pore volume of $0.160 \mathrm{~cm}^{3} / \mathrm{g}$. The catalyst samples showed a loss in residual surface area after each aging duration interval, but in each case the lean-only aging environment was the least severe condition and the redox aging environment was the most severe aging condition after 2 hours. The 2 hour lean treatment caused some surface area loss when applied after 20 minutes of aging, while the 2 hour and 16 hour aged samples were more stable. All three 20 minute aged samples showed an increased pore volume over fresh, perhaps from the aging temperature exceeding the calcination temperature, but the aging conditions soon sintered the pores as evidenced by the 2 hour and 16 hour data. The redox aging showed the most pore volume loss after 2 and 16 hours. CZO is a reducible support under these conditions and the repeated redox cycling was more degrading to CZO than the other environments at 2 hours and beyond.

\subsection{XRD Pattern Phase Identification}

The XRD patterns of the fresh, aged and post lean treated samples of $\mathrm{Pd} / \mathrm{CZO}$ are shown in Figure 2 and are consistent with the expected peaks for a CZO support. The fresh sample Pd [111] peak was indistinguishable in the XRD pattern apart from the background. Figure $2 a$ shows the XRD pattern after 20 minutes of aging. A slight appearance of a peak at $40^{\circ} 2 \theta$ emerged for the redox sample with a peak maximum of $40 \%$ above the average background measured at $42^{\circ} 2 \theta$. The $700^{\circ} \mathrm{C}$ lean treatment applied to the redox aged sample caused the $\mathrm{Pd}[111]$ peak to vanish. A Pd [111] peak fit of the redox aged sample resulted in a bulk diameter of $20 \mathrm{~nm}$, which was perhaps representing just the largest crystals. Pd particles less than $6 \mathrm{~nm}$ are often not distinguishable apart from the background XRD pattern. Therefore a significant number of the $\mathrm{Pd}$ particles on the 20 minute redox aged sample were likely below the detectable threshold. Figures $2 b$ and $2 c$ shows the XRD pattern after 2 hours and 16 hours of aging, respectively. A significant $\mathrm{Pd}$ [111] peak was observed at $40^{\circ} 2 \theta$ only for the redox and rich-only aged $\mathrm{Pd} / \mathrm{CZO}$ samples. The $700^{\circ} \mathrm{C}$ lean treatment decreased the area of the redox aged $\mathrm{Pd}$ [111] peak and shifted it slightly to a lower scattering angle of $39^{\circ} 2 \theta$, indicating an expanded lattice that are similar to the shift observed with Figure $2 \mathrm{~d} \beta-\mathrm{PdH}_{0.64}$ (reference card 04-002-0377).

\subsection{Average Pd Size Comparison}

The apparent Pd dispersion and Pd particle size for each sample are listed in Table 1. The Pd metal dispersion (D) was estimated as a function of the Pd particle size $\left(d_{P}\right)$ using equation 1 below, which is described further by Baylet et al. assuming spherical shapes [41]. 


$$
\mathrm{D}[\%]=\left(6 \times 10^{5}\right) *\left(M_{\mathrm{Pd}}\right) /\left(\rho_{\mathrm{Pd}} * S_{\mathrm{Pd}} * \mathrm{~d}_{\mathrm{P}}[\mathrm{nm}]\right) \quad \text { Equation } 1
$$

With $M_{P d}$ as the Pd atomic weight of $106.4 \mathrm{~g} / \mathrm{mol}, \rho_{P d}$ as the Pd density of $12 \mathrm{~g} / \mathrm{cm}^{3}, S_{P d}$ as the molar surface area of $\mathrm{Pd}$ metal of $47,780 \mathrm{~m}^{2} / \mathrm{mol}$ assuming an equidistribution of the low index faces.

The lean-only aging environment resulted in modest decreases in $\mathrm{Pd}$ dispersion with aging duration as measured by $\mathrm{H}_{2}$ chemisorption. The redox and rich-only aging environments at 2 hours and 16 hours each had undetectable $(\mathrm{u} / \mathrm{d}) \mathrm{Pd}$ surface area as measured by $\mathrm{H}_{2}$ chemisorption. $\mathrm{H}_{2}$ chemisorption provides a quantitative measurement of the exposed metal surface. Strong metal support interaction (SMSI) with Pd under reducing conditions are known to confound the results of this technique, as any reducible oxide support material can decorate or otherwise chemically inhibit $\mathrm{H}_{2}$ access to the metal surface $[42,43]$. The undetectable $\mathrm{Pd}$ surface area results after exposure to the rich-only conditions at $700^{\circ} \mathrm{C}$ is consistent with SMSI effects, although perhaps surprising after just 20 minutes. At 20 minutes of aging the $550^{\circ} \mathrm{C} / 2 \mathrm{~h}$ lean treatment provided a modest increase in $\mathrm{Pd}$ dispersion, while the $700^{\circ} \mathrm{C} / 2 \mathrm{~h}$ lean treatment restored the $\mathrm{Pd}$ dispersion completely to the level of the lean-only aging. These lean treatment $\mathrm{Pd}$ redispersion benefits diminished as the sample was allowed to accumulate a longer aging duration prior to the lean treatment application.

The changes in $\mathrm{Pd}$ size determined by $\mathrm{H}_{2}$ chemisorption was checked against the trends observed in XRD pattern Pd [111] peak fit estimates as shown in Table 2. The XRD Pd size estimate is a volumetric average technique and the result should be larger than the estimate from chemisorption, which is a surface average technique, while both techniques are weighted towards larger particles. The Pd particles in Table 2 were $21 \mathrm{~nm}$ or less and within the size range in the literature of $2-33 \mathrm{~nm}$ where crystallite length is synonymous with particle size, as those works used electron microscopy and chemisorption for confirmation [44, 45, 46, 47]. Note that crystallite length can be smaller than particle size if large particles are made of agglomerated crystals of if any poorly crystalline regions exist in the particle. The fresh and 20 minute aged samples were excluded from Table 2 as very small metal crystallites have excessively broad peaks that would not be completely detectable apart from the support diffraction pattern, since the width of the X-ray diffraction peak is inversely related to the crystallite length. The 2 hour and 16 hour rich-only and redox aged samples both showed $\mathrm{Pd}$ particles that were $17 \mathrm{~nm}$ and $20 \mathrm{~nm}$, respectively by XRD, which would result in 5-6\% dispersion if the Pd particles were not covered by support material through SMSI effects. No Pd size decrease was observed by XRD following the $550^{\circ} \mathrm{C} / 2 \mathrm{~h}$ lean treatment. However, the $700^{\circ} \mathrm{C} / 2 \mathrm{~h}$ lean treatment did show nearly a $33 \%$ reduction in $\mathrm{Pd}$ size on the 2 hour redox aged sample, yet a $10 \%$ reduction in $\mathrm{Pd}$ size on the 16 hour redox aged sample. After the $700^{\circ} \mathrm{C} / 2 \mathrm{~h}$ lean treatment, reasonable agreement in $\mathrm{Pd}$ size was shown for the two characterization techniques, since the SMSI effect was removed by oxidation and the sintered Pd particles were large enough to be detected apart from the background pattern. The XRD Pd size results confirm the diminishing benefit of the $700^{\circ} \mathrm{C}$ lean treatment the longer the sample is allowed to age.

\subsection{XPS Surface Characterization}

The XPS spectra of the fresh and redox aged Pd/CZO samples are shown in Figure 3. The Pd 3d peaks were fit under the raw data between the shoulders of the $\mathrm{Zr} 3 p$ peaks as is typically performed for analysis of $\mathrm{Pd}$ on CZO support [48, 49,50,51]. The fresh Pd/CZO sample had two $\mathrm{Pd} 3 \mathrm{~d}_{5 / 2}$ peaks, at $334.7 \mathrm{eV}$ for $\mathrm{Pd}$ metal and at $337.1 \mathrm{eV}$ for $\mathrm{Pd}^{+2}$. These results are consistent with those reported for $\mathrm{Pd}$ foil at $334.9 \mathrm{eV}$ and $\mathrm{PdO}$ at $336.8 \mathrm{eV}$ [52]. $\mathrm{Pd}$ 
peak shifting, due to redox aging or after a lean treatment, was not significant. However, redox aging suppressed the intensity of the $\mathrm{Pd}^{0}$ peaks and eliminated the $\mathrm{Pd}^{+2}$ peaks. The $700^{\circ} \mathrm{C} / 2 \mathrm{~h}$ lean treatments restored the $\mathrm{Pd}^{+2}$ peaks, in spite of the reduction pre-treatment. Four more $700^{\circ} \mathrm{C} / 30 \mathrm{~min}$ lean treatments were needed with the $16 \mathrm{~h}$ aged sample to achieve almost the same benefit observed with one lean treatment on the $2 \mathrm{~h}$ aged sample.

The XPS spectra of the Ce $3 d$ peaks are shown in Figure 4 . Neither the $\mathrm{Ce} 3 \mathrm{~d}_{5 / 2}$ peak at $882.0 \mathrm{eV}$ or the $\mathrm{Ce} 3 \mathrm{~d}_{3 / 2}$ peak at $900.4 \mathrm{eV}$ showed a shift due to redox aging or lean treatments. The other $\mathrm{Ce} 3 \mathrm{~d}$ peaks shown are satellite peaks that arise from interactions with the $\mathrm{Ce} 4 \mathrm{f}$ valence electrons after the $3 d$ core electron is emitted. Each core level $\left(3 d_{5 / 2}\right.$ and $3 d$ $3 / 2$ ) has 3 satellite peaks associated with it: the $3 d_{5 / 2}$ satellite peaks at $v^{\prime}=884.0 \mathrm{eV}, v^{\prime \prime}=889.1$ $\mathrm{eV}$ and v"' $=897.8 \mathrm{eV}$; and the $3 \mathrm{~d}_{3 / 2}$ satellite peaks at u' $=903.2 \mathrm{eV}, \mathrm{u}^{\prime \prime}=908.1 \mathrm{eV}$ and u'" = $916.3 \mathrm{eV}$. The u'" intensity varies linearly with the amount of $\mathrm{Ce}^{+4}$ and is fairly well separated from the rest of the peaks, enabling better estimation of the background. We can compare the signal from u'" to the intensity of the total envelope to get the percentage of $\mathrm{Ce}^{+4}$ on the surface. This technique is further described elsewhere [52].

The atomic concentrations from the top surface layers are shown in Table 2 based on the peak intensities shown in Figures 3 and 4. Adventitious carbon formed from exposure to room temperature air during the sample transfer and pellet pressing. While all catalyst samples were initially reduced prior to XPS evaluation, about half of the fresh $\mathrm{Pd}$ was still $\mathrm{Pd}^{+2}$, perhaps due to an abundance of interface sites with finely dispersed $\mathrm{Pd}$ and oxygen from $\mathrm{CeO}_{2}$. After 2 hours of redox aging, the surface concentration of $\mathrm{Pd}^{+2}$ species vanished and the total $\mathrm{Pd}$ signal was decreased by $70 \%$ relative to fresh. The $700^{\circ} \mathrm{C}$ lean treatment applied to the 2 hour aged sample restored $\mathrm{Pd}$ over the surface, reestablished the $\mathrm{Pd}^{+2}$ bonds with $\mathrm{Ce}$ up to the fresh level and lowered the surface concentration of $\mathrm{Ce}^{+3}$. After 16 hours of redox aging, the surface concentration of total $\mathrm{Pd}$ was decreased by $70 \%$ coincident with a surface concentration increase in $\mathrm{Ce}$ by $15 \%$ and $\mathrm{Zr}$ by $10 \%$, relative to fresh, without a significant increase in oxygen. This effect is consistent with $\mathrm{Pd}$ surface coverage by $\mathrm{Ce}$ [53]. The $700^{\circ} \mathrm{C}$ lean treatment applied to the 16 hour aged sample restored $\mathrm{Pd}$ over the surface, reestablished the $\mathrm{Pd}^{+2}$ bonds with $\mathrm{Ce}$ to near half of the fresh level and lowered the surface concentration of $\mathrm{Ce}^{+3}$. Another four $700^{\circ} \mathrm{C}$ lean treatments in 30 minute durations increased the amount of $\mathrm{Pd}^{+2}$, but again not to the level of the fresh catalyst. This improvement of exposed $\mathrm{Pd}$ surface from redox aged to $700^{\circ} \mathrm{C} / 2 \mathrm{~h}$ air regeneration agrees with the $\mathrm{H}_{2}$ chemisorption measurements in Table 1. XRD does not detect surface coverage by support, but does confirm that the Pd particle size decreased following the lean treatment from $17 \mathrm{~nm}$ to $11 \mathrm{~nm}$ for the 2 hour redox aged sample and from $20 \mathrm{~nm}$ to $18 \mathrm{~nm}$ for the 16 hour redox aged sample. These Pd particle sizes are all within the detection depth of the XPS instrument so the dramatic loss in $\mathrm{Pd}$ surface concentration from fresh to redox aged was most likely due to CZO support coverage and not Pd sintering.

\subsection{Infrared measurements}

The wave numbers characteristic to $\mathrm{CO}$ adsorption onto ceria, single $\mathrm{Pd}$ crystals and supported Pd particles are well studied $[54,55,56,57]$ and summarized in Table 4 . However, the IR band wave numbers are known to change with temperature, pressure and CO coverage $[58,59]$. Therefore the corresponding species given in Table 4 are approximate.

Figure 5 shows the IR spectra of uncatalyzed $\mathrm{CZO}$ and $\mathrm{Pd} / \mathrm{CZO}$ samples during $\mathrm{CO}$ adsorption at $22^{\circ} \mathrm{C}$. Spectra of the adsorbed species are the difference between the absorbance of the $\mathrm{CO}$ saturated sample and the clean sample background. As spectra for all 
samples were collected during flowing $\mathrm{CO}$, gas phase $\mathrm{CO}$ appears as two similar bands starting at $2050 \mathrm{~cm}^{-1}$ through $2200 \mathrm{~cm}^{-1}$ with high frequency and low amplitude. The peaks for CO adsorbed on $\mathrm{Pd}$ linear and bridge sites from 1800-2000 $\mathrm{cm}^{-1}$ are shown for just the fresh and redox aged with $700^{\circ} \mathrm{C} / 2 \mathrm{~h}$ air treatment samples. The similarly sized CO-Pd linear adsorption IR peak at $2050-2080 \mathrm{~cm}^{-1}$ for these two samples suggests a comparable number of these sites, but the CO-Pd bridge sites appear more abundant for the fresh sample likely due to higher Pd dispersion results from Table 1. CO adsorption onto $\mathrm{Pd}$ is not observed for the $\mathrm{Pd} / \mathrm{CZO}$ redox aged or $\mathrm{Pd} / \mathrm{CZO}$ redox aged with $550^{\circ} \mathrm{C} / 2 \mathrm{~h}$ air treatment samples through two hours, which aligns with the undetectable chemisorption results from Table 1 for these samples, and provides evidence for coverage of $\mathrm{Pd}$ by SMSI with $\mathrm{CeO}_{2}$ due to exposure to a high temperature reducing environment, in agreement with Badri et al. [30], since $\mathrm{ZrO}_{2}$ is not reducible under these conditions.

The growth rate of carbonates and formates from $1000-1700 \mathrm{~cm}^{-1}$ in Figure 5 showed the following trend: fresh $\mathrm{Pd} / \mathrm{CZO}>\mathrm{Pd} / \mathrm{CZO}$ redox aged with $700^{\circ} \mathrm{C} / 2 \mathrm{~h}$ air $>\mathrm{Pd} / \mathrm{CZO}$ redox aged with $550^{\circ} \mathrm{C} / 2 \mathrm{~h}$ air $>\mathrm{Pd} / \mathrm{CZO}$ redox aged $>\mathrm{CZO}$. This large difference between uncatalyzed $\mathrm{CZO}$ and the $\mathrm{Pd} / \mathrm{CZO}$ samples implies that $\mathrm{Pd}$ enhances the formation of carbonates and formates at the Pd-CZO interface sites. For the Pd samples, the growth rate appears to be directly related to $\mathrm{Pd}$ dispersion results in Table 1 . The difference in growth rate provides supporting evidence for the $\mathrm{H}_{2}$ chemisorption results reported in Table 1.

\subsection{Catalytic Activity}

$\mathrm{CO}_{2}$ production can be measured directly by the mass spectrometer in units of partial pressure (i.e, torr) and can be combined with the other measured gas species to determine the total pressure and thus enable a relative concentration calculation for each gas species. Micromoles of $\mathrm{CO}_{2}$ per gram of catalyst can be calculated for the OSC experiment using equation 2 below where the average $\mathrm{CO}_{2} 20$ seconds before and after the $\mathrm{CO}$ pulse is used as the background:

$$
\begin{aligned}
& \text { OSC } \mathrm{CO}_{2} \\
& {[\mu \mathrm{moles} / \mathrm{g}]}
\end{aligned}=\frac{\begin{array}{c}
\text { (current } \left.\mathrm{CO}_{2}[\%]-\text { background } \mathrm{CO}_{2}[\%]\right)^{*} \\
(\mathrm{CO} \text { pulse length }[\mathrm{m}])^{*}(\text { gas flow rate }[\mathrm{L} / \mathrm{m}])
\end{array}}{\text { Eq at room temperature })^{*}(22.414 \mathrm{~L} / \mathrm{mole}){ }^{*}(\text { mass }[\mathrm{g}])} \quad \text { Equation } 2
$$

Conversion of $\mathrm{CO}$ to $\mathrm{CO}_{2}$ during the WGS experiment can be calculated using equation 3 below where the average $\mathrm{CO}_{2}$ at room temperature is used as a background:

$$
\begin{aligned}
& \text { WGS conversion of } \\
& \text { CO to } \mathrm{CO}_{2}[\%]=
\end{aligned} \quad \begin{array}{ll}
\left.100 * \text { (current } \mathrm{CO}_{2}-\text { background } \mathrm{CO}_{2}\right) \\
(\mathrm{CO} \text { at room temperature })
\end{array} \text { Equation } 3
$$

The generation of $\mathrm{CO}_{2}$ over the $\mathrm{Pd} / \mathrm{CZO}$ samples at $300^{\circ} \mathrm{C}$ is shown in Figure 6 for the OSC test and in Figure 7 for the WGS test. In each case the lean-only aging environment was the least deteriorated. The rich-only aging environment was the harshest environment after 20 minutes, but after 2 hours the redox environment was the worst. The $550^{\circ} \mathrm{C} / 2 \mathrm{~h}$ lean treatment showed a modest improvement for the rich-only and redox aged samples, but the $700^{\circ} \mathrm{C} / 2 \mathrm{~h}$ lean treatment achieved restoration up to the lean-only aged sample. The OSC test of the most active catalysts at $350^{\circ} \mathrm{C}$ and $400^{\circ} \mathrm{C}$ showed complete consumption of $\mathrm{CO}$ so that the $\mathrm{CO}_{2}$ conversion results were limited relative to the poorer catalysts. In all cases, the poorest performing catalysts were also the ones that had below $4 \% \mathrm{Pd}$ dispersion measured by $\mathrm{H}_{2}$ 
chemisorption as shown in Table 1.

\subsection{PdO Formation Observed by HTXRD}

PdO formation observed in air by XRD measurement of $\mathrm{Pd}$ [111] peak disappearance required samples that had well-defined $\mathrm{Pd}$ [111] peaks as shown in Figure 2. This study therefore excluded the 20 minute aged samples and the lean-only aged samples at all durations. In addition, we sought to avoid confounding of the Pd oxidation rate by SMSI effects such as partial encapsulation or decoration of $\mathrm{Pd}$ with $\mathrm{Ce}^{+3}$. Therefore the $2 \mathrm{~h}$ and $16 \mathrm{~h}$ redox aged plus $700^{\circ} \mathrm{C} / 2 \mathrm{~h}$ lean treated samples were selected. The difference in bulk Pd size between these samples as shown in Table 2 was assumed significant enough to provide discrimination of $\mathrm{PdO}$ reoxidation rates.

Long sampling times were required for acceptable signal to noise diffraction patterns due to the large width of the beam $(\sim 1 \mathrm{~mm})$ and the limited positional resolution of the detector $(0.3$ $\mathrm{mm})$, causing relatively low instrumental resolution $\left(\sim 0.36^{\circ}\right)$ compared to conventional focusing diffractometers. Figure 8 shows the results of scans acquired at various durations to observe the $\mathrm{Pd}[111]$ peak from the $\mathrm{Pd} / \mathrm{CZO}$ redox aged sample. The signal to noise ratio is defined as the signal average divided by the standard deviation of the background, and a value of at least 5 is considered sufficient for distinguishing features from the background. The Pd[111] peak was well resolved apart from the background and not affected by the CZO support peaks as shown in Figures 2 and 8 . Scans were spaced at $0.015^{\circ} 2 \theta$ intervals, providing 64 data points across each $1^{\circ} 2 \theta$ interval. The signal value was the average peak height at $38.8-39.8^{\circ} 2 \theta$ minus the average height of the background at $37-38^{\circ} 2 \theta$ and $41-42^{\circ} 2 \theta$. The initial signal to noise ratio for the data in Figure 8 was 6 for the four minute scan, while it was 4 for the two minute scan. Therefore the four minute scan was considered an effective balance between fast data acquisition and low noise.

The long measurement times needed to monitor the $\mathrm{Pd}$ particle growth limited the accessible temperature range of the measurement. At sufficiently high temperatures, the growth of Pd particles becomes too fast for the HTXRD measurement acquisition time needed and an alternative method is needed to estimate the growth rate. To enable this approach, an accurate model of the time dependence of the growth is needed. The calculations used for the PdO phase fraction appearance during the HTXRD experiment are based on the AvramiErofe'ev model equation for the kinetics of phase transformations [60,61]. The linearized Avrami-Erofe'ev model equation relates the growth of an emerging phase fraction $\alpha$ at time $t$, rate constant $\mathrm{k}$, and growth exponent $\mathrm{n}$ as shown by equation 4 below.

$$
\alpha=1-\exp (-k t)^{\mathrm{n}} \quad \text { Equation } 4
$$

By plotting the phase fraction against time on a log-log scaling, $\mathrm{k}$ and $\mathrm{n}$ can be easily extracted assuming a linearized version as shown by equation 5 below.

$$
\ln (\ln [1 /(1-\alpha)])=n * \ln (k)+n * \ln (t) \quad \text { Equation } 5
$$

The values of $k$ were then plotted against inverse absolute temperature to determine the Arrhenius relationship and extract the activation energy $E_{a}$ and frequency constant $A$ by fitting the rate constants at the temperatures of each measurement by equation 6 below: 


$$
k=A^{*} \exp \left(-E_{a} / R T\right)
$$

Equation 6

An XRD pattern with the initially reduced $\mathrm{Pd}[111]$ peak at a low temperature of interest was acquired under nitrogen and the area under the peak was integrated for the $100 \% \mathrm{Pd}$ baseline at time zero $\left(\mathrm{t}_{0}\right)$. Once complete, air was introduced and acquisition began immediately of XRD patterns for the measurement of the Pd [111] peak at each time interval (t). At each scan time interval $(\mathrm{t}), \operatorname{Pd}[111](\mathrm{t})$ was equal to the peak intensity integrated from 38.8$39.8^{\circ} 2 \theta$ minus the background intensity integrated from $37-38^{\circ} 2 \theta$ and $41-42^{\circ} 2 \theta$. The $\mathrm{PdO}$ fraction at time $t$ was determined by equation 7 below:

$$
\mathrm{PdO}(\mathrm{t})=1-\left(\mathrm{Pd}[111](\mathrm{t}) / \mathrm{Pd}[111]\left(\mathrm{t}_{0}\right)\right) \quad \text { Equation } 7
$$

The PdO formation rate increased as a function of time and temperature as shown in Figure 9, plots a and b. The measured data was fit using the linearized Avrami model, yielding similar slopes with discrete intercepts at each measured temperature. Table 5 lists the average growth constant, $\mathrm{n}$, and oxidation rate, $\mathrm{k}$, determined from the fits in Figure 8 of the slope and intercept, respectively. The average value of the growth parameter $\mathrm{n}$ was 0.36 across the measured temperature range, corresponding to a $t^{0.36}$ relationship in the Avrami model, is similar to the $t^{1 / 3}$ growth relationship with fine Pd powder oxidation as studied by Matsui et al. [62]. Figure 10 shows a linear trend of the reaction rates plotted as an Arrhenius relationship with each measured temperature. Figure 10 lists the linear data fit equation, and activation energy, $E_{a}$, and constant, $A$, determined from the slope and intercept of the data fits. The rate parameter, $\mathrm{k}$, for the $2 \mathrm{~h}$ redox aged/regenerated sample was about twice that of the $16 \mathrm{~h}$ redox aged/regenerated sample for each temperature. From Table 2, the Pd particle size of the 2 hours aged/regenerated sample was $8.8 \mathrm{~nm}$ by chemisorption or $11 \mathrm{~nm}$ by XRD while the 16 hour aged/regenerated sample was $13 \mathrm{~nm}$ by chemisorption or $18 \mathrm{~nm}$ by XRD. Therefore the smaller $\mathrm{Pd}$ size (and higher $\mathrm{Pd}$ dispersion as per equation 1) led to faster oxidation. It is therefore important to keep $\mathrm{Pd}$ smaller than $8.8 \mathrm{~nm}$ to achieve rapid oxidation for possible redispersion during a brief vehicle fuel cut.

The above point can be further emphasized through a simplified extrapolation of the PdO formation rate at $700^{\circ} \mathrm{C}$ by working the above process in reverse. An extrapolated rate $\mathrm{k}$ at $700^{\circ} \mathrm{C}$ may be determined with equation 6 , since $E_{a}$ and $A$ are known, then the $\mathrm{PdO}$ formation with time at $700^{\circ} \mathrm{C}$ may be determined with equation 4 with the average $n$ value of 0.36 and the extrapolated rate k. Given a 10 second fuel cut at $700^{\circ} \mathrm{C}$, such an extrapolation for each $\mathrm{Pd} / \mathrm{CZO}$ sample would yield as follows: the 2 hour aged/regenerated sample would have $55 \%$ $\mathrm{PdO}$ while the 16 hour aged/regenerated sample would have $37 \% \mathrm{PdO}$, assuming no initial $\mathrm{PdO}$, uncovered Pd surfaces and a dry air environment. So it is important to maintain Pd particles smaller than $8.8 \mathrm{~nm}$ as neither sample was predicted to be completely oxidized within 10 seconds. However, any high temperature extrapolation may not hold up to scrutiny given expected $\mathrm{Pd}$ sintering at $700^{\circ} \mathrm{C}$ (demonstrated by our aging results) or support coverage of $\mathrm{Pd}$ by SMSI in redox conditions in as little as 20 minutes. Sintering rates and SMSI of Pd are negligible under the measurement conditions at $350^{\circ} \mathrm{C}$ in nitrogen, or during the air pulse, and are not reflected in the measured parameters. 


\subsection{PdO Formation Observed by TGA}

Figure 11 shows the result of TGA measurements for $\mathrm{PdO}$ decomposition in $\mathrm{N}_{2}$, and confirmation of the HTXRD measurements of $\mathrm{PdO}$ formation rate at $350^{\circ} \mathrm{C}$ and the simplified extrapolation of the $\mathrm{PdO}$ formation rate at $700^{\circ} \mathrm{C}$. The sample used for TGA analysis was the same $16 \mathrm{~h}$ redox aged/regenerated sample from the HTXRD measurements. However, the initial condition of the sample had to be different for the two techniques. The TGA sample was oxidized to limit confounding weight gain by CZO oxygen uptake, while the HTXRD sample was reduced in order to view the $\mathrm{Pd}$ [111] peak. Figure 11a shows the PdO decomposition plot in $\mathrm{N}_{2}$ to $700^{\circ} \mathrm{C}$ used to prepare the Pd metal for oxygen uptake. The derivative weight shows peak oxygen release near $600^{\circ} \mathrm{C}$. The maximum theoretical weight gain for the complete $\mathrm{Pd}$ oxidation of $77 \mathrm{mg}$ of $1.5 \mathrm{wt} \% \mathrm{Pd} / \mathrm{CZO}$ sample was determined to be $0.174 \mathrm{mg}$. The actual weight loss of $0.146 \mathrm{mg}$ reveals a reduction of $84 \%$ compared to the theoretical value, so the weight loss could be from just the $\mathrm{PdO}$ and not the $\mathrm{CeO}_{2}$ in the support. The sample oven temperature was then adjusted to either $350^{\circ} \mathrm{C}$ or $700^{\circ} \mathrm{C}$. In both Figure $11 \mathrm{~b}$ and $11 \mathrm{c}, 10 \% \mathrm{O}_{2}$ was fed to the sample and a weight gain was observed. The calculated theoretical maximum weight gain of $0.174 \mathrm{mg}$ was multiplied by the PdO formation fraction measured by HTXRD or extrapolated as a function of time by equation 4 above to obtain the weight gain by HTXRD in air. Weight gained was divided by the calculated theoretical maximum to obtain a fraction of PdO formation by TGA in $10 \% \mathrm{O}_{2}$. For Figure $11 \mathrm{~b}$ and $11 \mathrm{c}$, the results with TGA in $10 \% \mathrm{O}_{2}$ was similar in trend, yet just below that observed with HTXRD in air. The difference in Pd oxidation for the two techniques may be due to the higher amount of oxygen in the HTXRD feed stream or the lower extent of $\mathrm{Pd}$ reduction prior to the oxidation pulse with the TGA sample. The good consistency of the TGA and HTXRD measurements allows for estimation of the oxidation rates to temperatures beyond the range accessible by the HTXRD method. From the extrapolation, we are able to further estimate the effectiveness of the lean treatments to achieve redispersion and infer a recommendation for a practical engine control strategy.

\subsection{Effect of Additional Brief Lean Treatments}

Figure 12 shows the result of additional dry lean treatments on the Pd dispersion for the redox aged samples. With one 2 hour lean treatment, these redox aged-regenerated samples showed lower dispersion than the equivalent duration lean-only aged samples, except for the 20 minute redox aged-regenerated sample, which was just above the level of the lean-only 20 minute aged sample. The 20 minute redox aged sample may not have had the Pd covered by CZO after redox aging, but no confirmation of Pd redispersion by XRD was possible to confirm the improvement shown by $\mathrm{H}_{2}$ chemisorption in Table 1. Additional 30 minute pulses of dry air at $700^{\circ} \mathrm{C}$ were applied to achieve essentially complete oxidation of $\mathrm{Pd}$ on both samples with each pulse. The 20 minute redox aged-regenerated sample showed slight increases in $\mathrm{Pd}$ dispersion with each 30 minute dry air pulse up to the fresh level. The 2 hour redox agedregenerated sample showed a substantial increase in Pd dispersion with the first 30 minute dry air pulse to just above the level of the lean-only 2 hours aged sample, but the second 30 minute dry air pulse showed no further improvement. The 16 hour redox aged-regenerated sample also showed a substantial increase in Pd dispersion with the first 30 minute dry air pulse, but the result was just below the level of the lean-only 16 hours aged sample. A second 30 minute dry air pulse showed further improvement to above the level of the lean-only 16 hours aged sample, but the next two pulses did not bring further improvement. Multiple lean treatments were likely needed due to the CZO support covering the Pd surface after redox aging, where the first pulse decomposed the CZO that prevented some PdO wetting and spreading. It appears that the lean treatment has limitations with improving $\mathrm{Pd}$ dispersion to the equivalent duration lean-only aged sample and this upper limit may be linked to residual catalyst surface area. 


\section{Discussion}

\subsection{Aging environment}

Model powder catalysts showed dynamic changes to $\mathrm{Pd}$ dispersion depending on oxygen concentration in the $700^{\circ} \mathrm{C}$ aging environment. For the $\mathrm{Pd} / \mathrm{CZO}$ samples, the rich-only and redox environments caused much more severe loss of Pd dispersion than the fixed leanonly exhaust gas compositions, producing samples with the lowest activity for the WGS and OSC tests. Exposure to dry air at $700^{\circ} \mathrm{C}$ caused the Pd dispersion to increase as measured by both $\mathrm{H}_{2}$ chemisorption and XRD techniques. Based on these observations, one approach to maintain $\mathrm{Pd}$ dispersion on a catalytic converter is to manage engine operation so that the exhaust gas composition falls along a trajectory that avoids the fuel-rich environment or includes periodic fuel shut-off events during high speed driving conditions to reoxidize $\mathrm{Pd}$ into $\mathrm{PdO}$ to redisperse the $\mathrm{Pd}$.

\subsection{Aging duration}

Studies on $\mathrm{Pd}$ sintering have shown the rapid particle agglomeration and loss of $\mathrm{Pd}$ dispersion as a function of aging duration $[3,8]$. Recent studies of atomically dispersed $\mathrm{Pd}$ noted that subnanometer agglomerates of $\mathrm{Pd}$ atoms were easy to redisperse through a $700^{\circ} \mathrm{C}$ calcination, while larger $\mathrm{PdO}$ particles were found to be very stable in air and did not sinter up to $800^{\circ} \mathrm{C}[24,63]$. Peterson et al. speculated that the stability of bulk PdO may not allow it to be so easily redispersed as smaller Pd particles [63]. This agrees with earlier observations linking Pd particle size to the onset of $\mathrm{PdO}$ formation, wetting, spreading and rupture [20, 23]. Our focus here was to determine for how long operation at highway driving exhaust temperatures could be maintained while still allowing for effective regeneration of the activity lost due to $\mathrm{Pd}$ agglomeration. As the $\mathrm{Pd} / \mathrm{CZO}$ catalyst is aged longer, the lean treatment becomes less effective and appeared to become limited to the dispersion achieved after lean-only aging as shown in Figure 12. Still, the 2 hour redox aged sample was able to achieve significant $\mathrm{Pd}$ redispersion comparable to that produced in the lean-only aged sample $(13 \% \mathrm{vs} .16 \%)$. However, there is another important factor to consider: Pd redispersion first requires PdO formation and only $\mathrm{Pd}$ particles of a size just a few nanometers in diameter could achieve reoxidation and redisperse during the mere seconds of air that would be supplied by a typical fuel cut. Based on the measured Pd oxidation rate and the measurements of Pd size by chemisorption, the $8.8 \mathrm{~nm} \mathrm{Pd}$ particles had twice the oxidation rate of the $13 \mathrm{~nm} \mathrm{Pd}$ particles. In addition, the simplified extrapolation of $\mathrm{PdO}$ formation on the $8.8 \mathrm{~nm} \mathrm{Pd}$ particles at $700^{\circ} \mathrm{C}$ suggests that even 10 seconds in air is not enough to achieve over $60 \%$ oxidation of $\mathrm{Pd}$. Therefore a fuel cut should be performed before the $\mathrm{Pd}$ particles reach $8.8 \mathrm{~nm}$ in diameter to enable the lean treatment to be more efficient, which suggests a fuel cut just after 20 minutes of $700^{\circ} \mathrm{C}$ stoichiometric (i.e., redox) operation. Depending on the aging history of the catalyst, this fuel cut frequency can be adapted to continuously maintain proper catalyst performance through lean $\mathrm{Pd}$ redispersion.

Due to the limitations of XRD for discerning finely dispersed Pd particles apart from the background pattern, we were not able to measure the PdO formation rate on the 20 minute redox aged-regenerated sample. Newton et al. acquired $\mathrm{Pd}$ oxidation data taken at the European Synchrotron Radiation Facility (ESRF) on Pd nanoparticles of $3 \mathrm{~nm}$ in diameter [28]. Further synchrotron work could be done to study Pd particles below an $8.8 \mathrm{~nm}$ diameter. 


\subsection{Support effects}

The benefits of lean treatments on $\mathrm{Pd}$ were slightly confounded by the SMSI effect between $\mathrm{Pd}$ and $\mathrm{CeO}_{2}$. In an electron microscopy study, Chen and Ruckenstein observed $\mathrm{Pd}$ on an alumina film with microscopy in a pure oxygen environment and observed that the smallest PdO crystallites $(<15 \mathrm{~nm})$ wet and spread over the surface at $350^{\circ} \mathrm{C}$ while the larger $\mathrm{PdO}$ crystallites did not [20]. Then at $500^{\circ} \mathrm{C}$, all $\mathrm{PdO}$ crystallites eventually moved about the surface, rupturing and fracturing of the spreading Pd crystallites was observed as a mechanism to form smaller particles. In our work, the $550^{\circ} \mathrm{C}$ regeneration on $16-20 \mathrm{~nm}$ Pd particles should have had an effect similar to that observed by Chen and Ruckenstein, but XRD did not confirm any significant bulk Pd crystal size decrease. Our XPS and DRIFTS results showed substantial coverage of the $\mathrm{Pd}$ by the CZO support that likely limited the mobility of $\mathrm{Pd}$ wetting and spreading over CZO. Other work has shown that ceria covering a Pd surface can be removed from just the $\mathrm{Pd}$ [111] surface when heated in air at $500^{\circ} \mathrm{C}$ [30], and completely decomposed when heated in air at $700^{\circ} \mathrm{C}$ [53]. These observations may explain the difference in $\mathrm{Pd}$ size reduction accomplished on the redox and rich-only aged $\mathrm{Pd} / \mathrm{CZO}$ samples with the lean treatments at $550^{\circ} \mathrm{C}$ versus $700^{\circ} \mathrm{C}$.

$\mathrm{Pd}$ was able to redisperse on the CZO support material as evidenced by the catalyst activity improvement and measured $\mathrm{Pd}$ size reduction of the $700^{\circ} \mathrm{C}$ lean treated redox aged samples versus the as-is redox aged samples. These results are consistent with Hickey et al. using $\mathrm{Pd}$ supported on $\mathrm{Ce}_{0.68} \mathrm{Zr}_{0.32} \mathrm{O}_{2}$ and aged on a redox cycle, showing a lower temperature for conversion of $\mathrm{CO}$ after a high temperature lean treatment although no chemisorption results were reported to demonstrate a lower Pd size [18]. Peterson et al. showed supported Pd clusters treated in air at $700^{\circ} \mathrm{C}$ or with $1 \% \mathrm{O}_{2}$ achieved atomically dispersed $\mathrm{Pd}^{+2}$ species that were more stable on $\mathrm{La}_{2} \mathrm{O}_{3}-\mathrm{Al}_{2} \mathrm{O}_{3}$ than on undoped alumina [63]. The observations of Peterson et al. also are consistent with our XPS results where $\mathrm{Pd}^{+2}$ was observed on the lean treated redox $\mathrm{Pd} / \mathrm{CZO}$ samples, even though it was reduced prior to analysis. The ability of $\mathrm{Pd}$ to form stable $\mathrm{Pd}^{+2}$ on the support surface oxide may be vital to achieving significant $\mathrm{Pd}$ size reduction when inside the conditions of the Pd redispersion zone.

\section{Conclusions}

The trends in the aging severity at $700^{\circ} \mathrm{C}$ for different $\mathrm{Pd} / \mathrm{CZO}$ sample aging methods for 2 hours and 16 hours were as follows: redox > rich-only $>>$ lean-only. Reducing conditions produced a loss in exposed Pd surface area that was consistent with SMSI effects with support $\mathrm{CeO}_{2}$. After each aging interval, the $700^{\circ} \mathrm{C} / 2 \mathrm{~h}$ lean treatment applied after redox aging always increased the $\mathrm{Pd}$ dispersion towards the level of the lean-only aged sample, but the magnitude of $\mathrm{Pd}$ dispersion recovery diminished with aging duration. These results show how quickly reducing conditions (i.e., engine fuel enrichment) and highway driving catalyst temperatures can deactivate $\mathrm{Pd} / \mathrm{CZO}$, and how frequent engine fuel-cut events must be delivered. We have shown the importance of maintaining $\mathrm{Pd}$ below $8.8 \mathrm{~nm}$ for efficient and rapid redispersion, and based on the increasing difficulty of achieving the same result for longer aging times, it is recommended that a fuel cut be performed just after 20 minutes of $700^{\circ} \mathrm{C}$ stoichiometric (redox) operation as a practical method to maintain activity.

The approach presented here combines several methods to elucidate the Pd particle size and dispersion at different temperatures, the fraction of reducible $\mathrm{Pd}$, the coverage of particles by the CZO support and the effects of various aging treatments on the effectiveness of 
a lean redispersion method. The good consistency of the measurements with established models for particle growth kinetics allows for estimation of the growth rates to temperatures beyond the range accessible by these methods. From these extrapolations, we are able to further estimate the effectiveness of the lean treatments to achieve redispersion and infer a recommendation for a practical engine control strategy. This approach fills a critical gap in catalyst aging measurements and allows for more confidence in applying engine control methods to preserve catalyst performance over the life of the vehicle.

\section{Acknowledgements}

The authors gratefully acknowledge the following sources of funding for this study: Ford University Research Program (URP), NSF GOALI grant \# CBET-1159279 and NSF grant \# DMR-9871177.

\section{References}

[1] J. Kašpar, P. Fornasiero, N. Hickey, "Automotive catalytic converters: current status and some perspectives", Catal. Today 77 (2003) 419-449

[2] M. Shelef, R. McCabe, "Twenty-five years after introduction of automotive catalysts: what next?", Catal. Today 62 (2000) 35-50

[3] A. Datye, Q. Xu, K. Kharas, J. McCarty, "Particle size distributions in heterogeneous catalysts: What do they tell us about the sintering mechanism?", Catal. Today 111 (2006) 59-67

[4] R. Goeke and A. Datye, "Model oxide supports for studies of catalyst sintering at elevated temperatures", Top. Catal. 46 (2007) 3-9

[5] L. Martín, J. Arranz, O. Prieto, R. Trujillano, M. Holgado, M. Galán, V. Rives, "Simulation three-way catalyst ageing Analysis of two conventional catalyst", Appl. Catal. B: Environ. 44 (2003) 41-52

[6] C. Bartholomew, "Mechanisms of catalyst deactivation", Appl. Catal. A: Gen. 212 (2001) 17-60

[7] R. McCabe, R. Useman, "Characterization of Pd-based Automotive Catalysts", Stud. Surf. Sci. Catal. 101 (1996) 355-368

[8] Q. Xu, K.C. Kharas, B.J. Croley, A.K. Datye, "The Sintering of Supported Pd Automotive Catalysts", ChemCatChem 3 (2011) 1004-1014

[9] Z. Han, J. Wang, H. Yan, J. Fan, "Performance of dynamic oxygen storage capacity, water-gas shift and steam reforming reactions over Pd-only three-way catalysts", Catal. Today 158 (2010) 481-489

[10] H. Vidal, J. Kašpar, M. Pijolat, G. Colon, S. Bernal, A. Cordón, V. Perrichon, F. Fally, "Redox behavior of $\mathrm{CeO}_{2}-\mathrm{ZrO}_{2}$ mixed oxides II. Influence of redox treatments on low surface area catalysts", Appl. Catal. B: Environ. 30 (2001) 75-85

[11] E. Mamontov, T. Egami, R. Brezny, M. Koranne, S. Tyagi, "Lattice Defects and Oxygen Storage Capacity of Nanocrystalline Ceria and Ceria-Zirconia", J. Phys. Chem. B, 104 (2000) 11110-11116

[12] T. Bunluesin, R. Gorte, G. Graham, "Studies of the water-gas-shift reaction on ceria-supported Pt, Pd, and Rh: implications for oxygen-storage properties", Appl. Catal. B: Environ. 15 (1998) 107-114

[13] R. J. Gorte, "Ceria in catalysis: from automotive applications to the water-gas shift reaction", AlChE J., 56(5) (2010) 1126-1135

[14] M. Zhao, M. Shen, J. Wang, W. Wang, "Influence of Pd Morphology and Support Surface Area on Redox Ability of $\mathrm{Pd} / \mathrm{Ce}_{0.67} \mathrm{Zr}_{0.33} \mathrm{O}_{2}$ under $\mathrm{CO}-\mathrm{He}$ Pulse and Transient $\mathrm{CO}-\mathrm{O}_{2}$ Measurements", Ind. Eng. Chem. Res. 46 (2007) 7883-7890

[15] L. Kępińiski, M. Wolcyrz, J. Okal, "Effect of Chlorine on Microstructure and Activity of $\mathrm{Pd} / \mathrm{CeO}_{2}$ Catalysts", J. Chem. Soc. Farad. Trans. 91 (1995) 507-515

[16] G. Graham, A. Shigapov, "Revised Model of Strain in Ceria-Zirconia Encapsulated Precious-Metal Particles", Catal. Lett., 81 (2002) 253-258 
[17] G. Graham, A. O'Neill, A. Chen, "Pd encapsulation in automotive exhaust-gas catalysts", Appl. Catal. A: Gen. 252 (2003) 437-445

[18] N. Hickey, P. Fornasiero, R. Di Monte, J. Kašpar, J. R. González-Velasco, M. A. Gutiérrez-Ortiz, M. P. González-Marcos, J. M. Gatica, S. Bernal, "Reactivation of aged model $\mathrm{Pd} / \mathrm{Ce}_{0.68} \mathrm{Zr}_{0.32} \mathrm{O}_{2}$ three-way catalyst by high temperature oxidising treatment", Chem. Commun. 1 (2004) 196-197

[19] X. Chen, Y. Cheng, C.Y. Seo, J.W. Schwank, R.W. McCabe, "Aging, re-dispersion, and catalytic oxidation characteristics of model $\mathrm{Pd} / \mathrm{Al}_{2} \mathrm{O}_{3}$ automotive three-way catalysts", Appl. Catal. B: Environ. 163 (2015) 499-509

[20] J.J. Chen, E. Ruckenstein, "Role of Interfacial Phenomena in the Behavior of Alumina-Supported Palladium Crystallites in Oxygen", J. Phys. Chem. 85 (1981) 1606-1612

[21] N.M. Rodriguez, S.G. Oh, R.A. Dalla-Betta, R.T.K. Baker, "In-situ Electron Microscopy Studies of Palladium Supported on $\mathrm{Al}_{2} \mathrm{O}_{3}, \mathrm{SiO}_{2}$, and $\mathrm{ZrO}_{2}$ in Oxygen", J. Catal., 157 (1995) 676-686

[22] E. Ruckenstein, J. J. Chen, "Wetting Phenomena during Alternating Heating in $\mathrm{O}_{2}$ and $\mathrm{H}_{2}$ of Supported Metal Crystallites", J. Coll. Interf. Sci. 86 (1982) 1-11

[23] H. Lieske, J. Völter, "Pd Redispersion by Spreading of $\mathrm{PdO}$ in $\mathrm{O}_{2}$ Treated $\mathrm{Pd} / \mathrm{Al}_{2} \mathrm{O}_{3}$ ", J. Phys. Chem. 89 (1985) 1841-1842

[24] T.R. Johns, R.S. Goeke, V. Ashbacher, P.C. Thüne, J.W. Niemantsverdriet, B. Kiefer, C.H. Kim, M.P. Balogh, A.K. Datye, "Relating adatom emission to improved durability of Pt-Pd diesel oxidation catalysts", J. Catal. 328 (2015) 151-164

[25] R. J. Farrauto, J. K. Lampert, M. C. Hobson, E. M. Waterman, "Thermal decomposition and reformation of PdO catalysts; support effects" Appl. Catal. B: Environ. 6 (1995) 263-270

[26] M. Peuckert, "XPS Study on Surface and Bulk Palladium Oxide, Its Thermal Stability, and a Comparison with Other Noble Metal Oxides", J. Phys. Chem. 89 (1985) 2481-2486

[27] J. Nunan, J. Lupescu, G. Denison, D. Ball, D. Moser. "HC Traps for Gasoline and Ethanol Applications", SAE Int. J. Fuels and Lubrs. 6(2) (2013) 430-449

[28] M.A. Newton, C. Belver-Coldeira, A. Martínez-Arias, M. Fernández-García, “'Oxidationless” Promotion of Rapid Palladium Redispersion by Oxygen during Redox $\mathrm{CO} /\left(\mathrm{NO}+\mathrm{O}_{2}\right)$ Cycling", Angew. Chem. Int. Ed. 46 (2007) 8629-8631

[29] J.A. Lupescu, J.W. Schwank, K.A. Dahlberg, C.Y. Seo, G.B. Fisher, S.L. Peczonczyk, K. Rhodes, M.J. Jagner, L.P. Haack, "Pd Model Catalysts: Effect of Aging Environment and Lean Redispersion", Appl. Catal. B: Environ. in press (2015)

[30] A. Badri, C. Binet, J.-C. Lavalley, "Metal-support interaction in $\mathrm{Pd} / \mathrm{CeO} 2$ catalysis Part 2. - Ceria textural effects", J. Chem. Soc. Farad. Trans. 92(9) (1996) 1603-1608

[31] H.P. Sun, X.P. Pan, G.W. Graham, H.-W. Jen, R.W. McCabe, S. Thevuthasan, C.H.F. Peden, "Partial encapsulation of Pd particles by reduced ceria-zirconia", Appl. Phys. Lett. 87 (2005) 201915

[32] L. Kępińiski, M. Wolcyrz, "Microstructure of $\mathrm{Pd} / \mathrm{CeO}_{2}$ catalyst: Effect of high temperature reduction in hydrogen", Appl. Catal. A: Gen. 150 (1997) 197-220

[33] T.P. Bebee, J.T. Yeates, "'Spectroscopic Detection of (111) Facets on Supported Pd Crystallites: Site Blocking by Ethyldyne on $\mathrm{Pd} / \mathrm{Al}_{2} \mathrm{O}_{3}$ ", Surf. Sci. Lett. 173 (1986) L606-L612

[34] R.F. Hicks, A.T. Bell, "Effects of Metal-Support Interactions on the Hydrogenation of $\mathrm{CO}$ over $\mathrm{Pd} / \mathrm{SiO}_{2}$ and $\mathrm{Pd} / \mathrm{La}_{2} \mathrm{O}_{3}$ ", J. Catal. 90 (1984) 205-220

[35] D. Briggs, M.P. Seah, Practical Surface Sci. Analysis by Auger and X-ray Photoelectron Spectroscopy, John Wiley \& Sons, New York, 1984

[36] J. E. Benson, H. S. Hwang, M. Boudart, "Hydrogen-Oxygen Titration Method for the Measurement of Supported Palladium Surface Areas", J. Catal 30 (1973) 146-153

[37] V. Ragaini, R. Giannantonio, P. Magni, L. Lucarelli, G. Leofanti, "Dispersion Measurement by the Single Introduction Method Coupled with the Back-Sorption Procedure: A Chemisorption and TPD Study of the Different Chemisorbed Hydrogen Species II. Pd on Alumina", J. Catal. 146 (1994) 116-125

[38] T. Takeguchi, S. Manabe, R. Kikuchi, K. Eguchi, T. Kanazawa, S. Matsumoto, W. Ueda, "Determination of dispersion of precious metals on $\mathrm{CeO}_{2}$-containing supports", Appl. Catal. A: Gen. 293 (2005) 91-96

[39] A.L. Patterson, "The Scherrer Formula for X-Ray Particle Size Determination", Phys. Rev. 56 (1939) 978-982

[40] S. Colussi, A. Trovarelli, E. Vesselli, A. Baraldi, G. Comelli, G. Groppi, J. Llorca, "Structure and morphology of $\mathrm{Pd} / \mathrm{Al}_{2} \mathrm{O}_{3}$ and $\mathrm{Pd} / \mathrm{CeO}_{2} / \mathrm{Al}_{2} \mathrm{O}_{3}$ combustion catalysts in $\mathrm{Pd}-\mathrm{PdO}$ transformation hysteresis", Appl. Catal. A: Gen. 390 (2010) 1-10 
[41] A. Baylet, S. Royer, P. Marécot, J. Tatibouët, D. Duprez," Effect of Pd precursor salt on the activity and stability of Pd-doped hexaaluminate catalysts for the $\mathrm{CH}_{4}$ catalytic combustion", Appl. Catal. B: Environ. 81 (2008) 88-96

[42] R.F. Hicks, Q.-J. Yen, A.T. Bell, "Effects of Metal-Support Interactions on the Chemisorption of $\mathrm{H}_{2}$ and $\mathrm{CO}$ on $\mathrm{Pd} / \mathrm{SiO}_{2}$ and $\mathrm{Pd} / \mathrm{La}_{2} \mathrm{O}_{3}$ ", J. Catal. 89 (1984) 498-510

[43] J.S. Rieck, A.T. Bell, "Studies of the Interactions of $\mathrm{H}_{2}$ and $\mathrm{CO}$ with $\mathrm{Pd} / \mathrm{SiO}_{2}$ Promoted with $\mathrm{La}_{2} \mathrm{O}_{3}$, $\mathrm{CeO}_{2}, \mathrm{Pr}_{6} \mathrm{O}_{11}, \mathrm{Nd}_{2} \mathrm{O}_{3}$, and $\mathrm{Sm}_{2} \mathrm{O}_{3}$ ", J. Catal. 99 (1986) 278-292

[44] C.R. Adams, H.A. Benesi, R. M. Curtis, R. G. Meisenheimer, "Particle Size Determination of Supported Catalytic Metals: Platinum on Silica Gel", J. Catal. 1, (1962) 336-344

[45] J.K. Plischke, M.A. Vannice, "Effect of Pretreatment on the Adsorption Properties of Silver Crystallites", Appl. Catal. 42 (1988) 255-283

[46] R.T.K Baker, E.B. Prestridge, G.B. McVicker, "The Interaction of Palladium with Alumina and Titanium Oxide Supports" J. Catal. 89 (1984) $422-432$

[47] F.M. Dautzenberg, H.B.M. Wolters, "State of Dispersion of Platinum in Alumina-Supported Catalysts" J. Catal. 51 (1978) 26-39

[48] L. Yang, X. Yang, S. Lin, R. Zhou, "Insights into the role of a structural promoter (Ba) in three-way catalyst Pd/CeO2-ZrO2 using in situ DRIFTS", Catal. Sci. Technol., 5 (2015) 2688-2695

[49] K. Tanikawa, C. Egawa, "Effect of barium addition on CO oxidation activity of palladium catalysts", Appl. Catal. A: Gen. 403 (2011) 12-17

[50] M. Zhao, X. Li, L. Zhang, C. Zhang, M. Gong, Y. Chen, "Catalytic decomposition of methanol to carbon monoxide and hydrogen over palladium supported on $\mathrm{Ce}_{0.65} \mathrm{Zr}_{0.30} \mathrm{La}_{0.05} \mathrm{O}_{2}$ and $\mathrm{La}-\mathrm{Al}_{2} \mathrm{O}_{3}$ ", Catal. Today 175 (2011) 430-434

[51] M.Y. Smirnov, G.W. Graham, "Pd oxidation under UHV in a model Pd/ceria-zirconia catalyst" Catal. Lett. 72 (2001) 39-44

[52] J.Z. Shyu, K. Otto, W.L.H. Watkins, G.W. Graham, R.K. Belitz, H.S.Gandhi, "Characterization of Pd Y-Alumina Catalysts Containing Ceria", J. Catal. 114 (1988) 23-33

[53] M. Alexandrou, R.M. Nix, "The growth, structure and stability of ceria overlayers on $\mathrm{Pd}(111)$ ", Surf. Sci. 321 (1994) 47-57

[54] A. Holmgren, B. Anderson, D. Duprez, "Interactions of CO with Pt/ceria catalysts", Appl. Catal. B: Environ. 22 (1999) 215-230

[55] G.N. Vayssilov, M. Mihaylov, P. St. Petkov, K.I. Hadjiivanov, K.M. Neyman, "Reassignment of the Vibrational Spectra of Carbonates, Formates, and Related Surface Species on Ceria: A Combined Density Functional and Infrared Spectroscopy Investigation", J. Phys. Chem. C 115 (2011) 2343523454

[56] N.B. Colthup, "Spectra-Structure Correlations in the Infra-Red Region", J. Optic. Soc. Amer. 40 (1950) 397- 400

[57] F.M. Hoffmann, "Infrared Reflection-Absorption Spectroscopy of Adsorbed Molecules", Surf. Sci. Rep. 3 (1983) 107-192

[58] J. Szanyi, W.K. Kuhn, D.W. Goodman, "CO adsorption on $\mathrm{Pd}(111)$ and $\mathrm{Pd}(100)$ : Low and high pressure correlations", J. Vac. Sci. Tech. A 11 (1993) 1969-1974

[59] S. Bertarione, D. Scarano, A. Zecchina, V. Johánek, J. Hoffmann, S. Schauermann, M.M. Frank, J. Libuda, G. Rupprechter, H.-J. Freund, "Surface Reactivity of Pd Nanoparticles Supported on Polycrystalline Substrates As Compared to Thin Film Model Catalysts: Infrared Study of CO Adsorption", J. Phys. Chem. B, 108 (2004) 3603-3613

[60] M. Avrami, "Kinetics of Phase Change. I General Theory", J. Chem. Phys. 7 (1939) 1103-1112

[61] M. Avrami, "Kinetics of Phase Change. II Transformation-Time Relations for Random

Distribution of Nuclei", J. Chem. Phys. 8 (1940) 212-224

[62] T. Matsui, T. Hoshikawa, K. Naito, "Oxidation of Simulated Fission-Produced Noble Metals and Alloy", Sol. Stat. Ion. 40/41 (1990) 996-999

[63] E.T. Peterson, A.T. DeLaRiva, S. Lin, R.S. Johnson, H. Guo, J.T. Miller, J.H. Kwak, C.H.F. Peden, B. Kiefer, L.F. Allard, F.H. Ribeiro, A.K. Datye, "Low-temperature carbon monoxide oxidation catalysed by regenerable atomically dispersed palladium on alumina", Nat. Commun. 5 (2014) 4885 


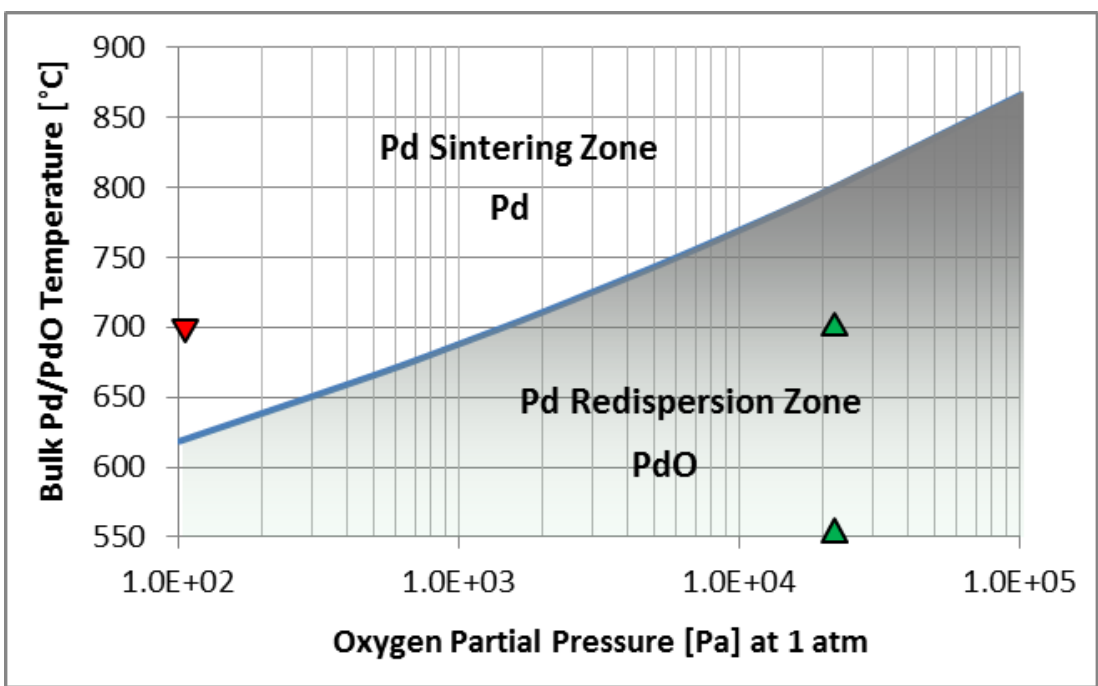

Figure 1: Bulk Palladium Oxide thermal stability using a published equation from reference [26]: $\log \left(\mathrm{pO}_{2} / 1 \mathrm{~Pa}\right)=15.8-12300 \mathrm{~K} / \mathrm{T}$. The red triangle represents the lean aging condition of $0.1 \% \mathrm{O}_{2}$ that is $80^{\circ} \mathrm{C}$ above the oxide decomposition temperature. The green triangles represent the lean treatment condition of $21 \% \mathrm{O}_{2}$ that are well below the oxide decomposition temperature. 


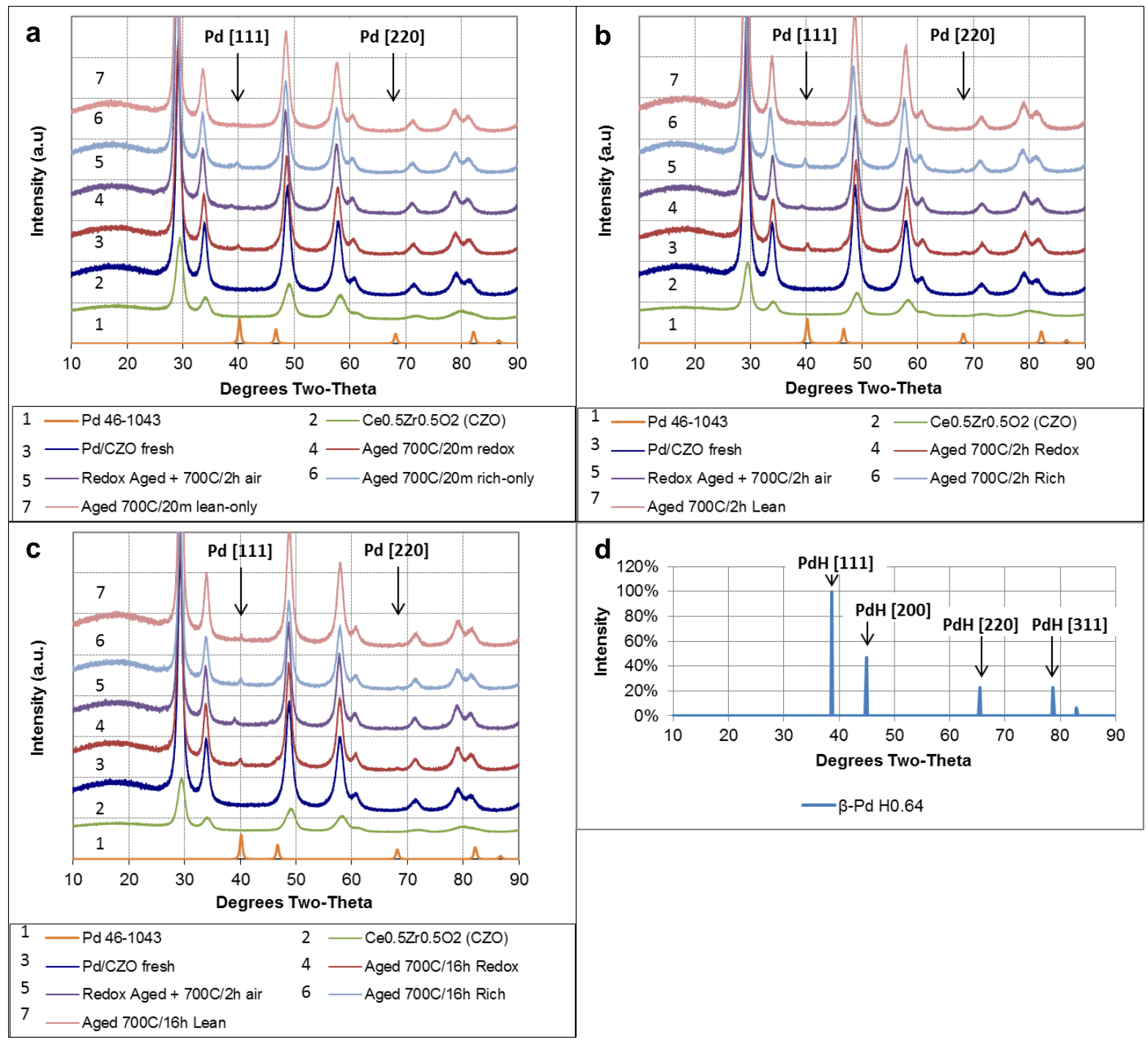

Figure 2: XRD pattern results. Plots for: a) 20 min aging, b) 2 hours aging, c) 16 hours aging, $d$ ) reference $\beta-\mathrm{PdH} 0.64$ 


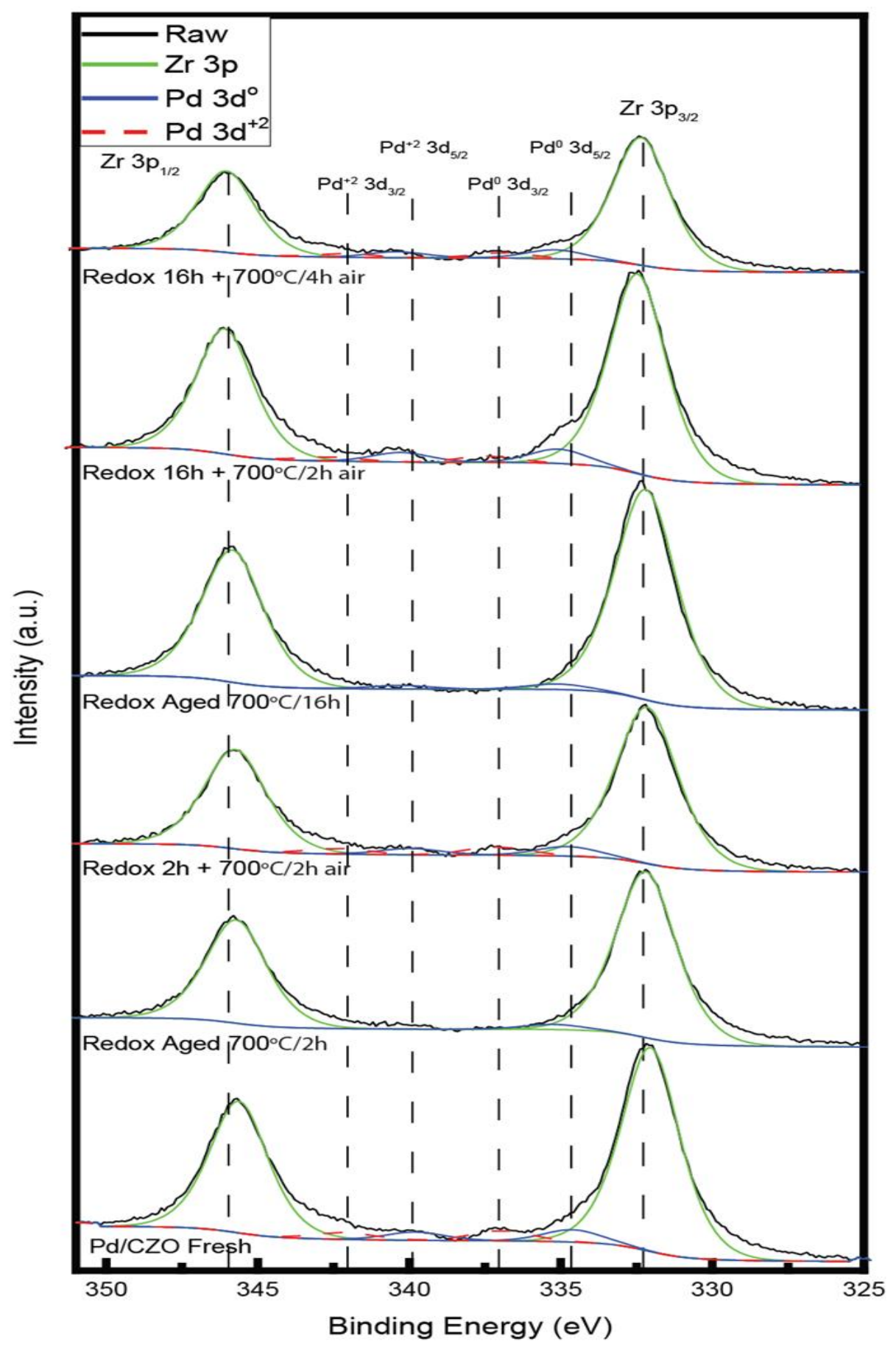

Figure 3: XPS Surface Analysis of Pd 3d. Solid blue lines are representative fits for $\mathrm{Pd}$ metal, dashed red lines are representative fits for $\mathbf{P d}^{+2}$. Spectra are offset for clarity. 

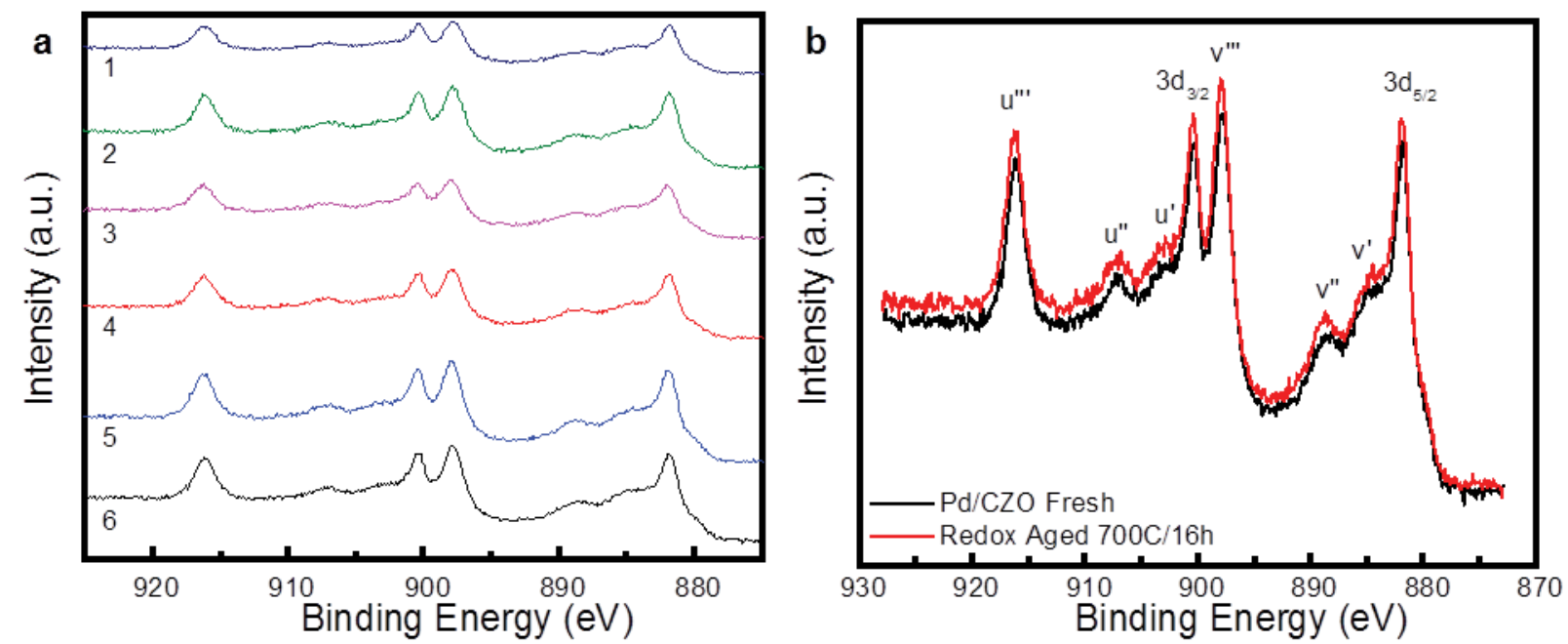

$1-$ Redox $2 \mathrm{~h}+700^{\circ} \mathrm{C} / 2 \mathrm{~h}$ air $4-$ Redox Aged $700^{\circ} \mathrm{C} / 16 \mathrm{~h}$

2 - Redox Aged $700^{\circ} \mathrm{C} / 2 \mathrm{~h} \quad 5-$ Redox $16 \mathrm{~h}+700^{\circ} \mathrm{C} / 2 \mathrm{~h}$ air

$3 \longrightarrow$ Redox $16 \mathrm{~h}+700^{\circ} \mathrm{C} / 4 \mathrm{~h}$ air $6 \longrightarrow \mathrm{Pd} / \mathrm{CZO}$ Fresh

Figure 4: XPS Surface Analysis of Ce 3d. Spectra are offset for clarity. Plots: a) Fresh and Redox Aged Samples and b) identified satellite peaks
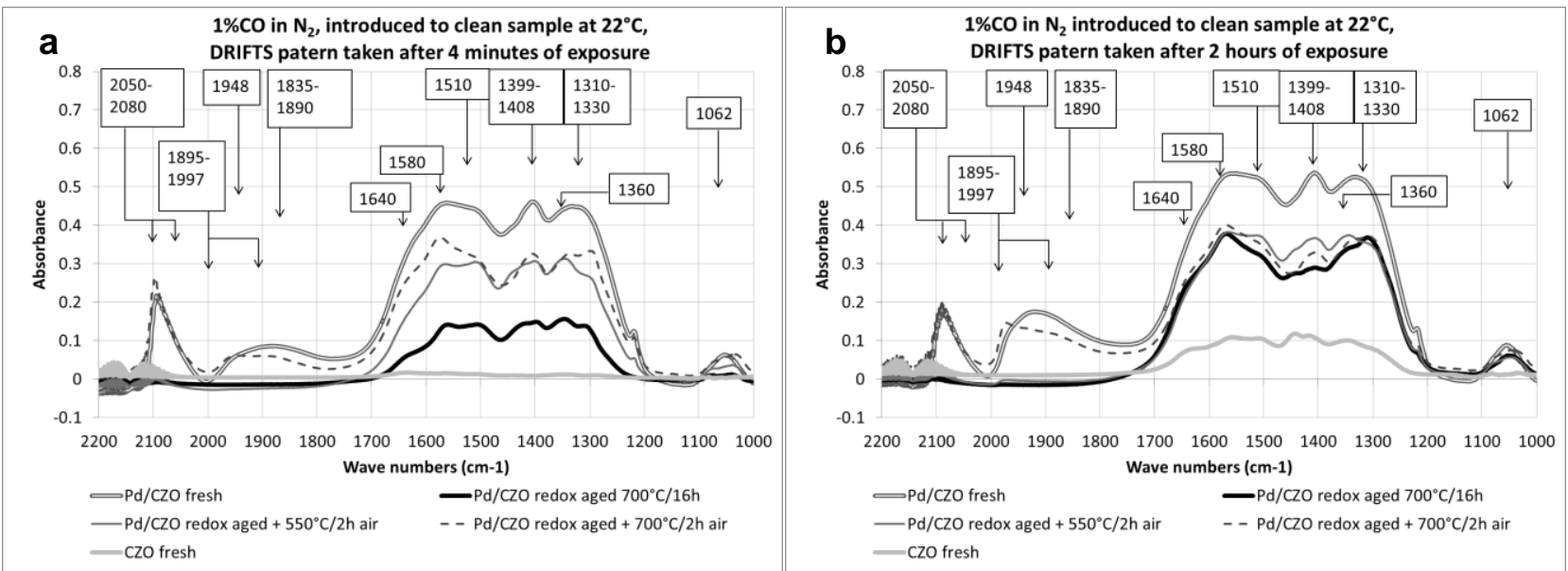

Figure 5: IR spectra during $\mathrm{CO}$ exposure to clean samples at $22^{\circ} \mathrm{C}$. Plots: a) after 4 minutes, b) after 2 hours 


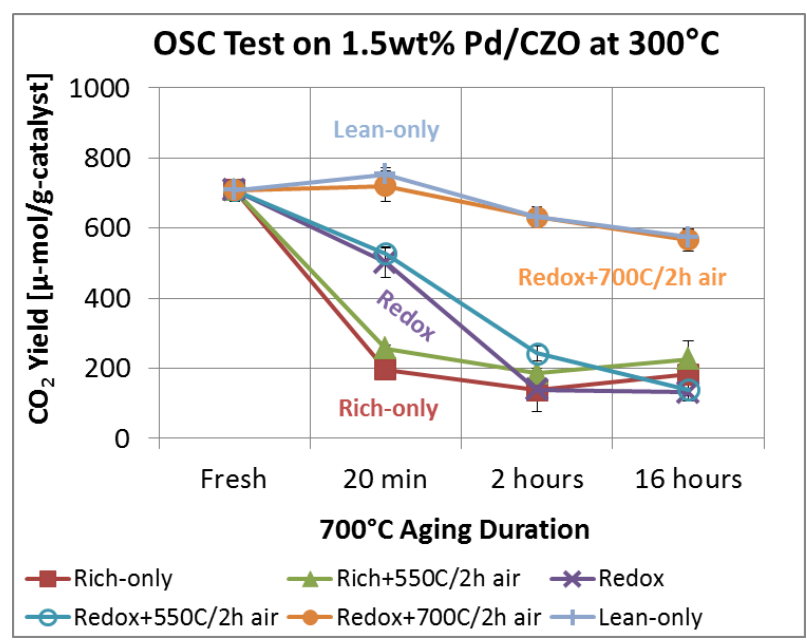

Figure 6: OSC test on Pd/CZO samples $\mathrm{CO}_{2}$ yield as a function of age

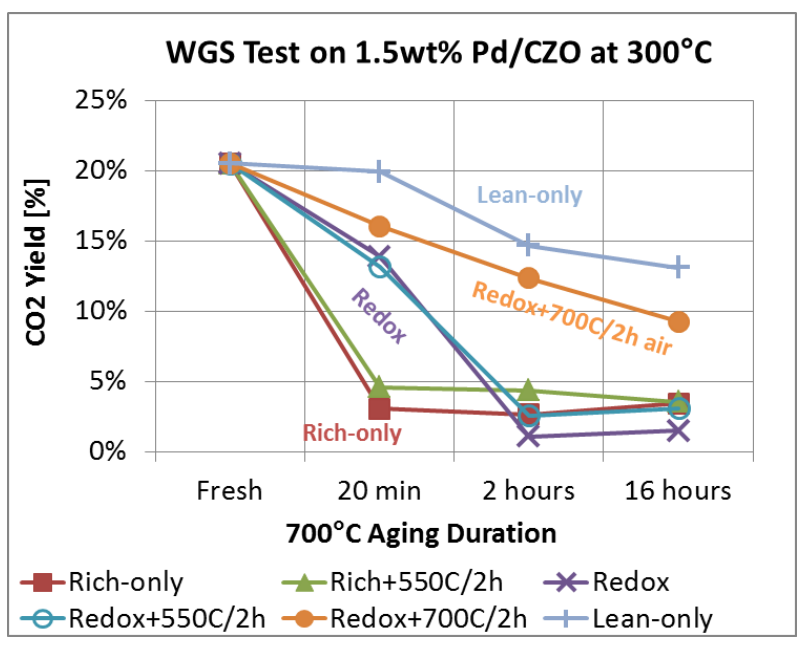

Figure 7: WGS test on Pd/CZO samples $\mathrm{CO}_{2}$ yield as a function of age

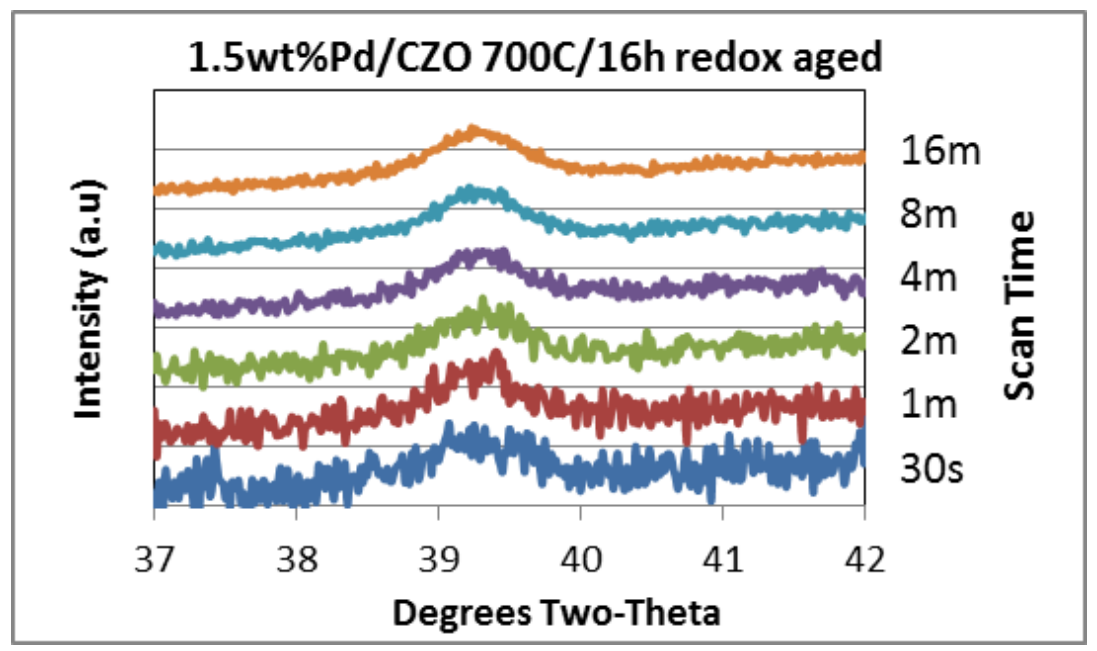

Figure 8: HTXRD data acquisition scans with Pd[111] on CZO 


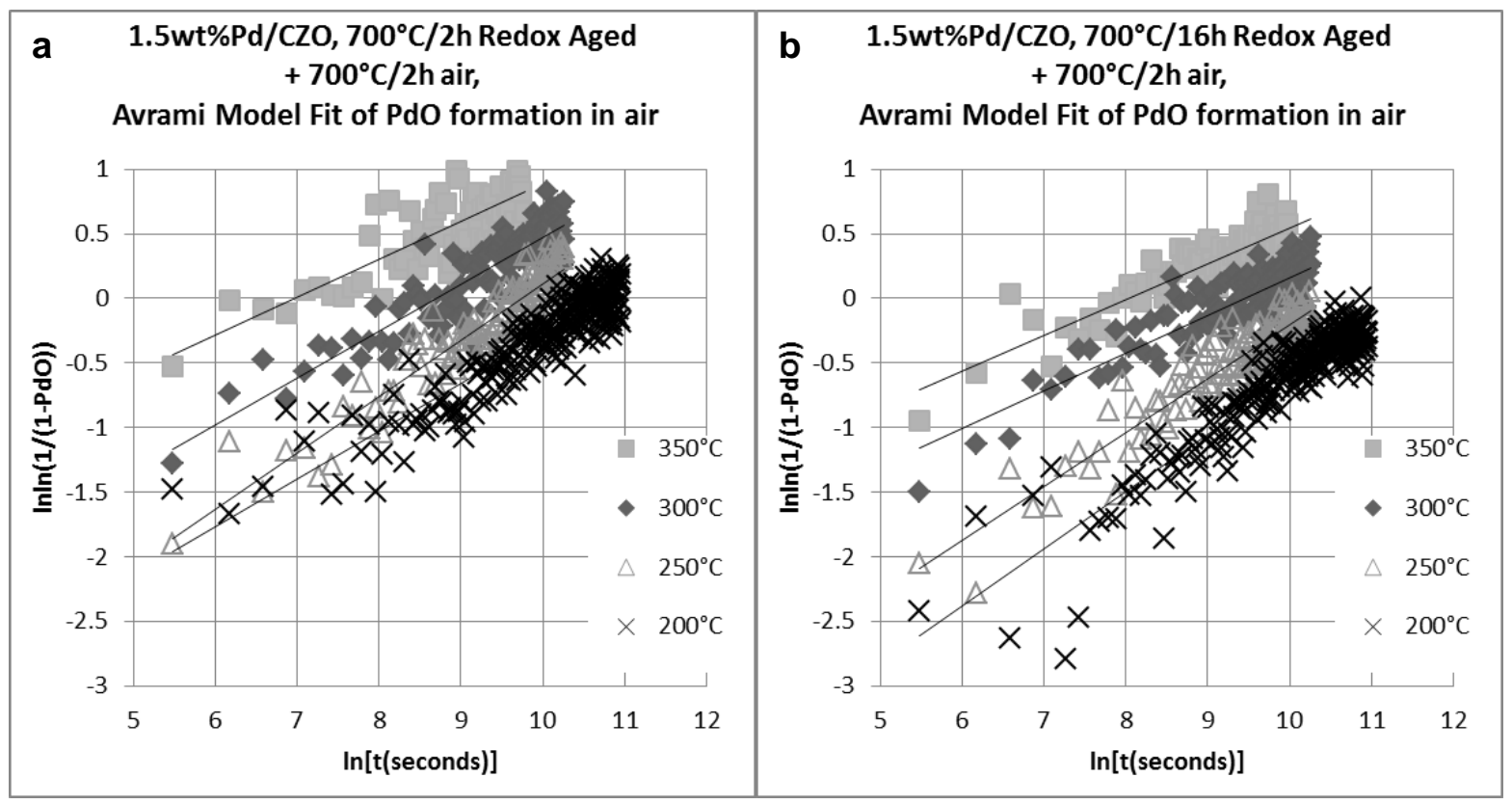

Figure 9: Measured and fit PdO formation rates in air at low temperature. Plots of redox aged-regenerated samples: a) $2 \mathrm{~h}$ fit data, b) $16 \mathrm{~h}$ fit data
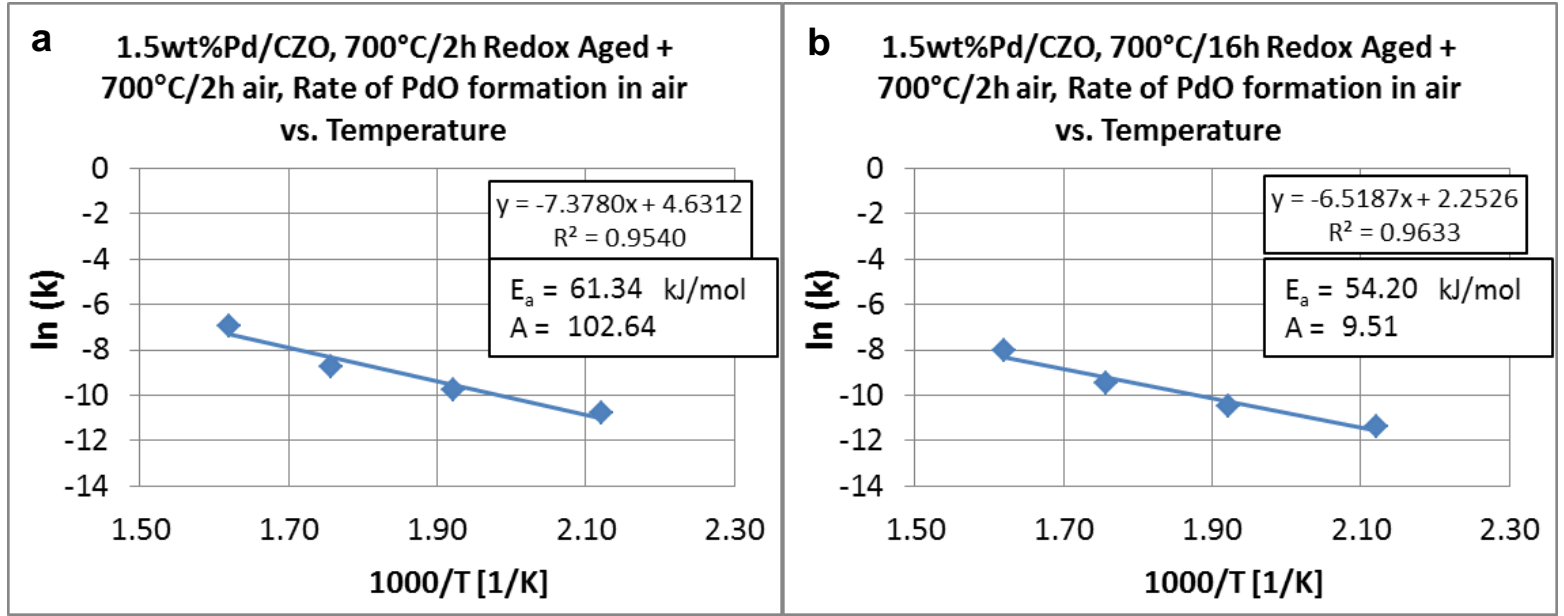

Figure 10: Arrhenius model fit of PdO formation rates in air at low temperature. Plots of redox aged-regenerated samples: a) $2 \mathrm{~h}$ fit data, b) $16 \mathrm{~h}$ fit data. 


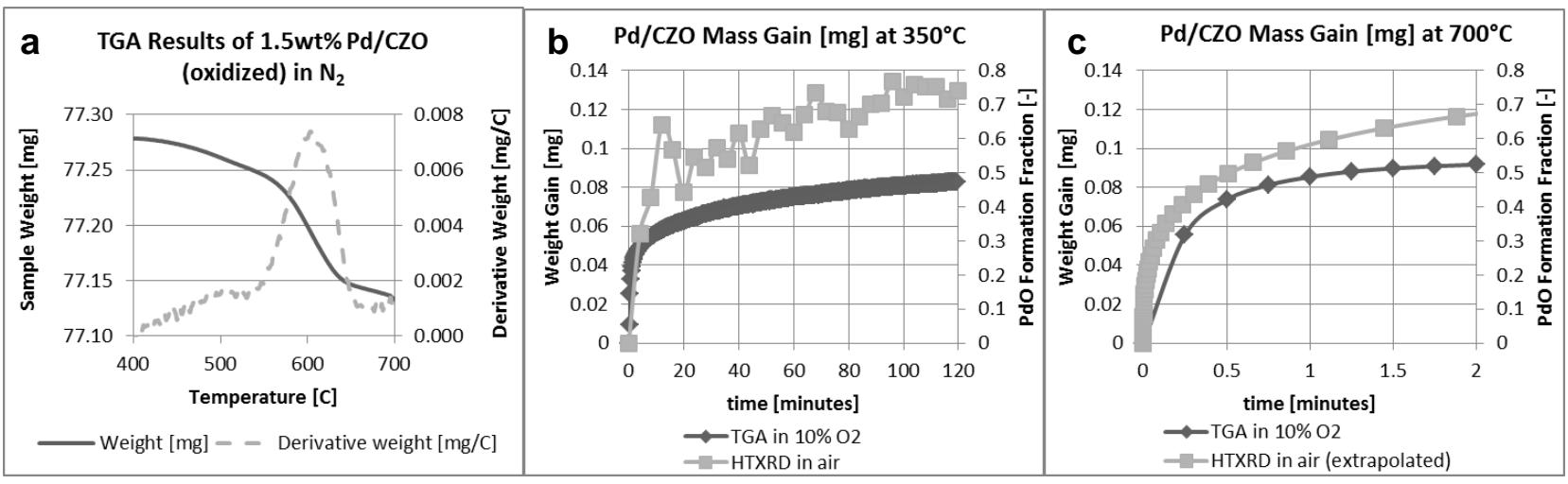

Figure 11: TGA results on $\mathrm{Pd} / \mathrm{CZO}$ redox aged $700^{\circ} \mathrm{C} / 16 \mathrm{~h}+700^{\circ} \mathrm{C} / 2 \mathrm{~h}$ air. Plots: a) $\mathrm{PdO}$ decomposition in $\mathrm{N}_{2}$, b) comparison to HTXRD results at $350^{\circ} \mathrm{C}$, c) comparison to $\mathrm{HTXRD}$ results extrapolated to $700^{\circ} \mathrm{C}$.

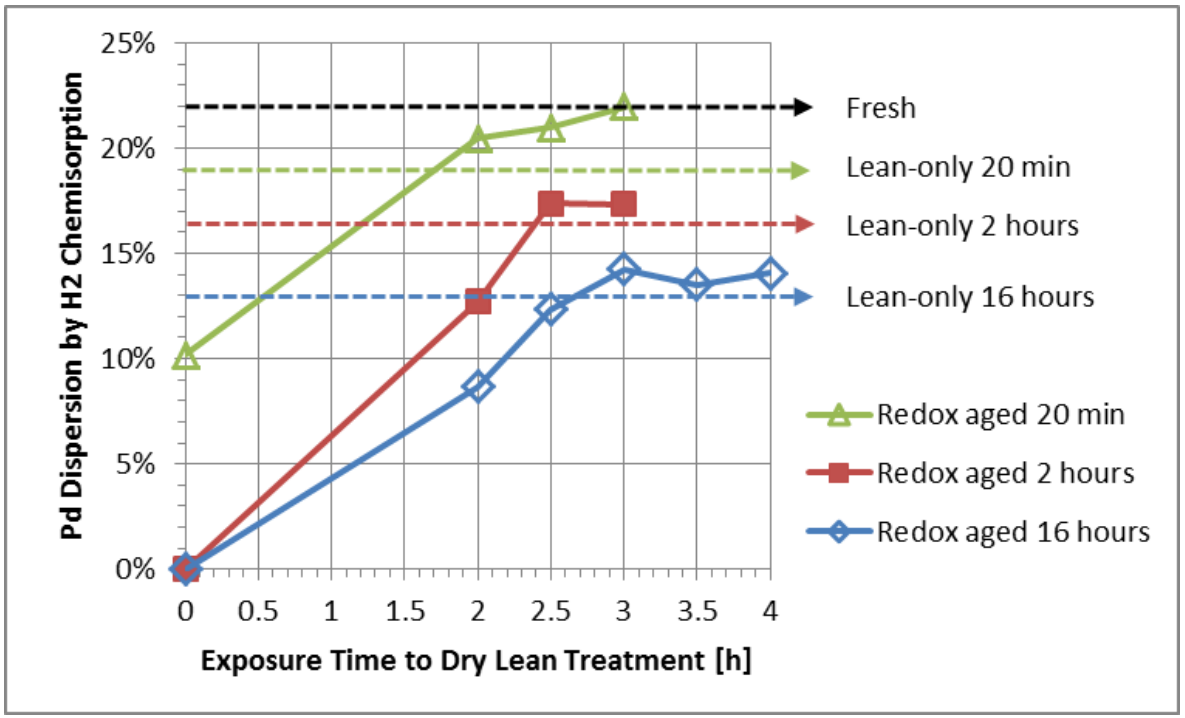

Figure 12: Effect of Additional Dry Lean Treatments 


\begin{tabular}{|c|c|c|c|c|c|}
\hline \multirow[b]{2}{*}{ Environment } & \multirow[b]{2}{*}{ Duration } & \multicolumn{2}{|c|}{$\mathrm{N}_{2}$ Physisorption } & \multicolumn{2}{|c|}{$\mathrm{H}_{2}$ Chemisorption } \\
\hline & & $\begin{array}{c}\text { Surface } \\
\text { Area }\left[\mathrm{m}^{2} / \mathrm{g}\right]\end{array}$ & $\begin{array}{c}\text { Pore Volume } \\
{\left[\mathrm{cm}^{3} / \mathrm{g}\right]}\end{array}$ & $\begin{array}{c}\text { Pd dispersion } \\
{[\%]}\end{array}$ & $\begin{array}{c}\text { Pd particle } \\
\text { size [nm] }\end{array}$ \\
\hline Fresh & - & 91 & 0.160 & $22 \%$ & 5.1 \\
\hline $\begin{array}{l}\text { Lean-only } \\
700^{\circ} \mathrm{C}\end{array}$ & $\begin{array}{l}20 \text { min } \\
2 \text { hours } \\
16 \text { hours }\end{array}$ & $\begin{array}{l}66 \\
59 \\
49 \\
\end{array}$ & $\begin{array}{l}0.162 \\
0.160 \\
0.159 \\
\end{array}$ & $\begin{array}{l}19 \% \\
16 \% \\
13 \% \\
\end{array}$ & $\begin{array}{l}5.8 \\
6.7 \\
8.6 \\
\end{array}$ \\
\hline $\begin{array}{l}\text { Rich-only } \\
700^{\circ} \mathrm{C}\end{array}$ & $\begin{array}{l}20 \text { min } \\
\quad+550^{\circ} \mathrm{C} / 2 \mathrm{~h} \text { air } \\
2 \text { hours } \\
\quad+550^{\circ} \mathrm{C} / 2 \mathrm{~h} \text { air } \\
16 \text { hours } \\
+550^{\circ} \mathrm{C} / 2 \mathrm{~h} \text { air }\end{array}$ & $\begin{array}{l}59 \\
53 \\
52 \\
48 \\
46 \\
44\end{array}$ & $\begin{array}{l}0.166 \\
0.152 \\
0.159 \\
0.154 \\
0.154 \\
0.154\end{array}$ & $\begin{array}{c}\mathrm{u} / \mathrm{d}^{\dagger} \\
3.6 \%^{\dagger} \\
\mathrm{u} / \mathrm{d}^{\dagger} \\
2.9 \%^{\dagger} \\
\mathrm{u} / \mathrm{d}^{\dagger} \\
2.0 \%^{\dagger}\end{array}$ & $\begin{array}{c}\mathrm{u} / \mathrm{d}^{\dagger} \\
30^{\dagger} \\
\mathrm{u} / \mathrm{d}^{\dagger} \\
38^{\dagger} \\
\mathrm{u} / \mathrm{d}^{\dagger} \\
55^{\dagger}\end{array}$ \\
\hline $\begin{array}{l}\text { Redox }(10 \mathrm{~min} \\
\text { lean } / 10 \mathrm{~min} \\
\text { rich) } 700^{\circ} \mathrm{C}\end{array}$ & $\begin{array}{l}20 \text { min } \\
\quad+550^{\circ} \mathrm{C} / 2 \mathrm{~h} \text { air } \\
+700^{\circ} \mathrm{C} / 2 \mathrm{~h} \text { air } \\
2 \text { hours } \\
\quad+550^{\circ} \mathrm{C} / 2 \mathrm{~h} \text { air } \\
+700^{\circ} \mathrm{C} / 2 \mathrm{~h} \text { air } \\
16 \text { hours } \\
+550^{\circ} \mathrm{C} / 2 \mathrm{~h} \text { air } \\
+700^{\circ} \mathrm{C} / 2 \mathrm{~h} \text { air }\end{array}$ & $\begin{array}{l}63 \\
60 \\
55 \\
51 \\
47 \\
52 \\
41 \\
40 \\
41\end{array}$ & $\begin{array}{l}0.163 \\
0.156 \\
0.156 \\
0.156 \\
0.151 \\
0.158 \\
0.150 \\
0.152 \\
0.149\end{array}$ & $\begin{array}{c}7.9 \%^{\dagger} \\
12 \% \\
20 \% \\
u / d^{\dagger} \\
2.1 \%{ }^{\dagger} \\
13 \% \\
u / d^{\dagger} \\
1.3 \%{ }^{\dagger} \\
8.7 \%\end{array}$ & $\begin{array}{c}14^{\dagger} \\
9.1 \\
5.4 \\
\mathrm{u} / \mathrm{d}^{\dagger} \\
52^{\dagger} \\
8.8 \\
\mathrm{u} / \mathrm{d}^{\dagger} \\
84^{\dagger} \\
13\end{array}$ \\
\hline
\end{tabular}

${ }^{\dagger} \mathrm{Pd}$ particles suspected to be covered or partially encapsulated

\begin{tabular}{|c|c|c|c|c|c|}
\hline \multicolumn{6}{|c|}{ Table 2: Comparison of Pd size characterization methods on $\mathrm{Pd} / \mathrm{CZO}$ samples } \\
\hline \multirow[b]{2}{*}{ Environment } & \multirow[b]{2}{*}{ Duration } & \multicolumn{2}{|c|}{$\mathrm{H}_{2}$ Chemisorption } & \multicolumn{2}{|c|}{ XRD Pd[111] peak fit } \\
\hline & & $\begin{array}{c}\text { Pd dispersion } \\
{[\%]}\end{array}$ & $\begin{array}{c}\text { Pd particle } \\
\text { size }[\mathrm{nm}]\end{array}$ & $\begin{array}{c}\text { Pd dispersion } \\
{[\%]}\end{array}$ & $\begin{array}{c}\text { Pd particle } \\
\text { size }[\mathrm{nm}]\end{array}$ \\
\hline \multirow{6}{*}{$\begin{array}{l}\text { Redox }(10 \mathrm{~min} \\
\text { lean } / 10 \mathrm{~min} \\
\text { rich) } 700^{\circ} \mathrm{C}\end{array}$} & 2 hours & $\mathrm{u} / \mathrm{d}^{\dagger}$ & $\mathrm{u} / \mathrm{d}^{\dagger}$ & $6.5 \%$ & 17 \\
\hline & $+550^{\circ} \mathrm{C} / 2 \mathrm{~h}$ air & $2.1 \%^{\dagger}$ & $52^{\dagger}$ & $5.3 \%$ & 21 \\
\hline & $+700^{\circ} \mathrm{C} / 2 \mathrm{~h}$ air & $13 \%$ & 8.8 & $10 \%$ & 11 \\
\hline & 16 hours & $\mathrm{u} / \mathrm{d}^{\dagger}$ & $\mathrm{u} / \mathrm{d}^{\dagger}$ & $5.4 \%$ & 20 \\
\hline & $+550^{\circ} \mathrm{C} / 2 \mathrm{~h}$ air & $1.3 \%^{t}$ & $84^{+}$ & $5.4 \%$ & 20 \\
\hline & $+700^{\circ} \mathrm{C} / 2 \mathrm{~h}$ air & $8.7 \%$ & 13 & $6.3 \%$ & 18 \\
\hline
\end{tabular}

${ }^{\dagger} \mathrm{Pd}$ particles suspected to be covered or partially encapsulated 


\begin{tabular}{|c|c|c|c|c|c|c|c|c|}
\hline Duration & Sample & C & 0 & $\mathrm{Ce}^{+3}$ & $\mathrm{Ce}^{+4}$ & $\mathbf{Z r}$ & $\mathbf{P d}^{0}$ & $\mathbf{P d}^{+2}$ \\
\hline $0 \min$ & Fresh & 20.9 & 59.9 & 2.0 & 4.0 & 12.6 & 0.29 & 0.28 \\
\hline \multirow{2}{*}{2 hours } & Redox $700^{\circ} \mathrm{C}$ & 24.9 & 58.6 & 1.4 & 4.0 & 10.8 & 0.16 & - \\
\hline & $+700^{\circ} \mathrm{C} / 2 \mathrm{~h}$ air & 25.2 & 58.8 & 1.2 & 4.6 & 9.4 & 0.40 & 0.29 \\
\hline \multirow{3}{*}{16 hours } & Redox $700^{\circ} \mathrm{C}$ & 22.8 & 56.2 & 1.9 & 5.0 & 13.9 & 0.16 & - \\
\hline & $+700^{\circ} \mathrm{C} / 2 \mathrm{~h}$ air & 24.1 & 57.8 & 1.3 & 4.3 & 11.9 & 0.35 & 0.16 \\
\hline & $+700^{\circ} \mathrm{C} / 4 \mathrm{~h}$ air & 27.9 & 54.1 & 1.3 & 4.2 & 11.9 & 0.35 & 0.21 \\
\hline
\end{tabular}

\begin{tabular}{|lcc|}
\hline \multicolumn{4}{|c|}{ Table 4: IR bands on CZO and Pd } & \\
\hline Species & Wave number [cm $^{-1}$ ] & Reference \\
\hline Carbonates bidentate & $1028,1286,1562$ & {$[54]$} \\
Carbonate unidentate & 1062,1454 & {$[54]$} \\
CO-Ce+4 linear & $1310-1330$ & {$[54]$} \\
Formates & 1360,1580 & {$[54]$} \\
Hydrogen carbonate & $1399-1408$ & {$[55]$} \\
Inorganic carboxylate & 1510,1560 & {$[54]$} \\
Aromatic C=C bending & $1500-1700$ & {$[56]$} \\
C=O stretch & 1650 & {$[56]$} \\
CO-Pd [111] bridge x3 & $1835-1890$ & {$[57]$} \\
CO-Pd [111] bridge x2 & 1948 & {$[57]$} \\
CO-Pd [100] bridge x2 & $1895-1997$ & {$[57]$} \\
CO-Pd [11] linear & $2050-2080$ & {$[57]$} \\
\hline
\end{tabular}

Table 5: Avrami model rate constant and exponent for measured PdO formation

\begin{tabular}{|c|c|c|c|c|}
\hline \multirow{2}{*}{$\begin{array}{c}\text { Temperature } \\
T\left({ }^{\circ} \mathrm{C}\right)\end{array}$} & \multicolumn{2}{|c|}{ Redox aged $700^{\circ} \mathrm{C} / 2 \mathrm{~h}+700^{\circ} \mathrm{C} / 2 \mathrm{~h}$ air } & \multicolumn{2}{|c|}{ Redox aged $700^{\circ} \mathrm{C} / 16 \mathrm{~h}+700^{\circ} \mathrm{C} / 2 \mathrm{~h}$ air } \\
\hline & $k(1 / s)$ & $n$ & $k(1 / s)$ & $n$ \\
\hline 200 & $2.06 \times 10^{-5}$ & 0.37 & $1.14 \times 10^{-5}$ & 0.44 \\
\hline 250 & $5.75 \times 10^{-5}$ & 0.43 & $2.79 \times 10^{-5}$ & 0.42 \\
\hline 300 & $1.64 \times 10^{-4}$ & 0.36 & $7.72 \times 10^{-5}$ & 0.29 \\
\hline 350 & $9.45 \times 10^{-4}$ & 0.29 & $3.24 \times 10^{-4}$ & 0.28 \\
\hline
\end{tabular}


Graphical Abstract:

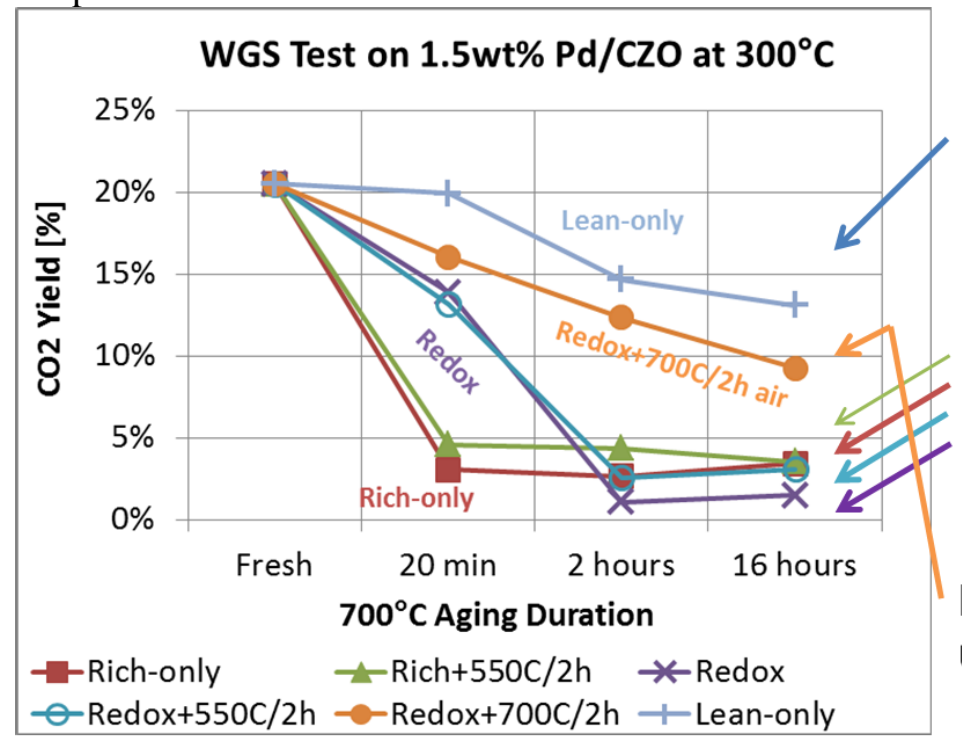

Small (5-9 nm), exposed Pd particles

Fresh or Lean Aged

Medium (17-21 nm), Ce covered Pd particles

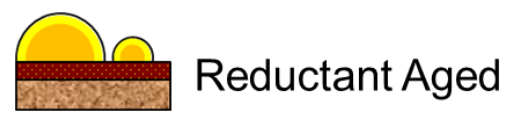

Medium ( $\leq 18 \mathrm{~nm}$ ), uncovered $\mathrm{Pd}$ particles

$\because \begin{aligned} & \text { Reductant Aged + } \\ & 700^{\circ} \mathrm{C} \text { Regenerated }\end{aligned}$ 